
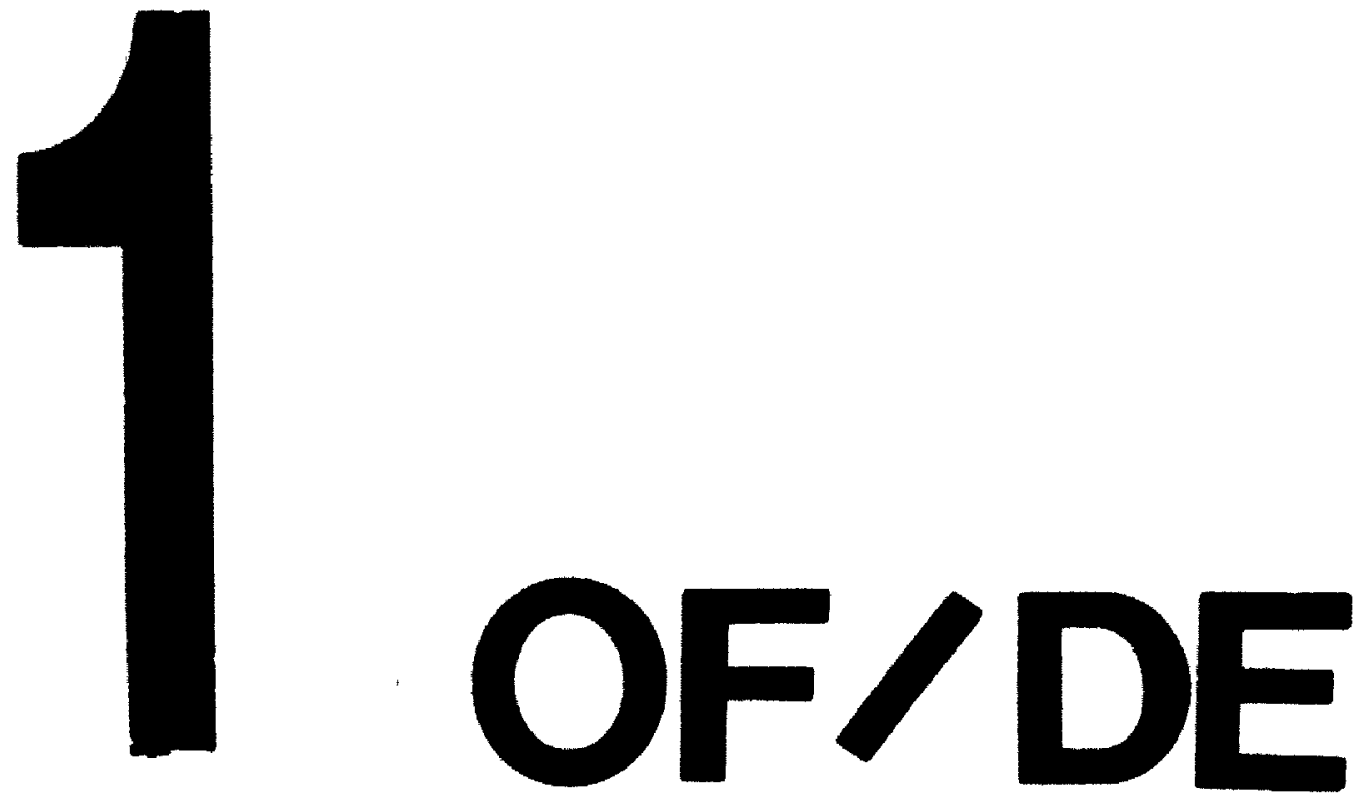

PM-1 $31 / 2$ " $\times 4$ " PHOTOGRAPHIC MICROCOPY TARCET NBS 1010a ANSt/1SO *2 EOUTVLENT

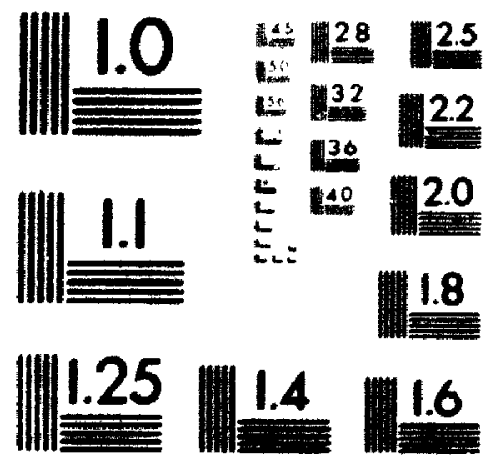


Acquisitions and

Bibliographic Services Branch

395 Wellington Street

Onawa, Ontario

KiA ONA4
Bibliotheque nationale

du Canada

Direction des acquisitions et

des services bibliographiques

395. rue Wellington

Ottawa (Ontaro)
NOTICE
AVIS
The quality of this microform is heavily dependent upon the quality of the original thesis submitted for microfilming. Every effort has been made to ensure the highest quality of reproduction possible.

If pages are missing, contact the university which granted the degree.

Some pages may have indistinct print especially if the original pages were typed with a poor typewriter ribbon or if the university sent us an inferior photocopy.
La qualité de cette microforme dépend grandement de la qualité de la thèse soumise au microfilmage. Nous avons tout fait pour assurer une qualité supérieure de reproduction.

S'il manque des pages, veuillez communiquer avec l'université qui a conféré le grade.

La qualité d'impression de certaines pages peut laisser à désirer, surtout si les pages originales ont été dactylographiées à l'aide d'un ruban usé ou si l'université nous a fait parvenir une photocopie de qualité inférieure.

La reproduction, même partielle, de cette microforme est soumise à la Loi canadienne sur le droit d'auteur, SRC 1970, c. C-30, et ses amen dements subséquents.
Reproduction in full or in part of this microform is governed by the Canadian Copyright Act, R.S.C. 1970, c. C-30, and subsequent amendments. 


\author{
Control of Penile Tumescence \\ in Convicted Child Molesters: \\ Effects of a Mid-Trial Change in stinulus Category
}

by

P. Bruce Malcoln

A thesis subnitted to the Department of Psychology in partial fulfilment for the requirements for the Degree of Master of Arts

Carleton University

Ottawa, Ontario, Canada

October 2, 1992 
National Library

of Canada

Acquisitions and

Bibliographic Services Branch

395 Wellington street

Ottema Onterio

KIA ONA
Bibliotheque nationals

du Canada

Direction des acquisitions et

des services bibliographiques

395. nue Wellington

Otama (Ontanio)
The author has granted an irrevocable non-exclusive licence allowing the National Library of Canada to reproduce, loan, distribute or sell copies of his/her thesis by any means and in any form or format, making this thesis available to interested persons.
L'auteur a accordé une licence irrévocable et non exclusive permettant a la Bibliotheque nationale du Canada de reproduire, prêter, distribuer ou vendre des coples de sa thése de quelque manière et sous quelque forme que ce soit pour mettre des exemplaires de cette these à la disposition des personnes intéressées.
The author retains ownership of the copyright in his/her thesis. Neither the thesis nor substantial extracts from it may be printed or otherwise reproduced without his/her permission.
L'auteur conserve la propriété du droit d'auteur qui prntège $8 \mathbf{8}$ these. Ni la these ni des extraits substantiels de celle-ci ne doivent être imprimés ou autrement reproduits sans son autorisation. 
The undersigned recommend to the Faculty of Graduate studies and Research acceptance of the thesis

Control of Penile Tumescence

in Convicted Child Molesters:

Effects of a Mid-Trial Change in Stimulus category

submitted by P. Bruce Malcolm, B.A.

in partial fulfilment of the requirements for

the degree of Master of Arts
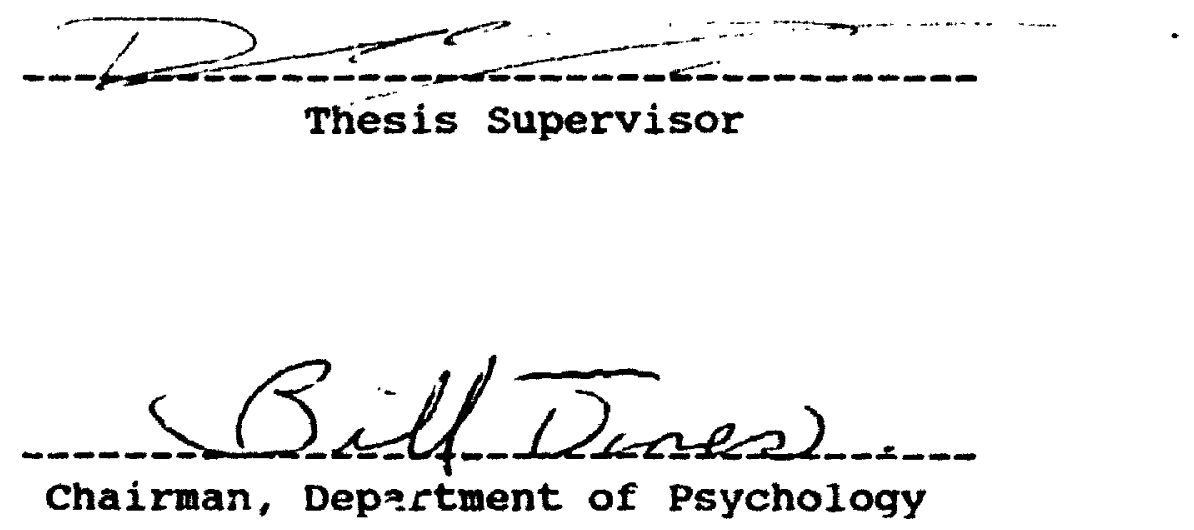

Carleton University

October, 1992 


\title{
Control of Penile Tumescence
}

\begin{abstract}
The present study investigated the ability of incarcerated child molesters and nonchild molester sex offenders to control ongoing penile tumescence, while being presented with stimuli of varying content. Penile tumescence changes were measured using a plethysmograph with mercury-in-rubber strain gauges. Subjects from both groups were presented erotic video tapes and instructed to allow themselves to become aroused. When the prescribed level of arousal was obtained (50\% of full erection) the video was stopped and a slide transparency was randomly presented from one of four categories. The four categories were: $1 /$ a neutral scene; $2 /$ a nude adult female; $3 /$ a nude pubescent female; and 4/ a nude prepubescent female. During presentation of these slide transparencies, subjects were instructed to reduce their level of arousal as much as possible while maintaining eye contact with the stimulus being presented. The results indicate that the ability to reduce ongoing penile tumescence is relatively more difficult when subjects are presented sexual stimuli compared to non-sexual stimuli. It was also found that preferred sexual stimuli interferred with the ability to
\end{abstract}




\section{Control of Penile Tumescence}

reduce ongoing arousal relative to nonpreferred sexual stimuli. The results are discussed in terms of implications for current assessment techniques as well as some ethical and theoretical concerns. 
Control of Penile Tumescence

iv

\section{Acknowledgements}

I would like to express my sincere appreciation to the Corrertional Service of Canada, and in particular Mr. Andrew Graham, for allowing me to attend carleton while continuing to receive a large portion of my salary. I will always be indebted to my supervisor Don Andrews for his guidance, patience and support throughout this and other projects. I wish also to thank Steve Wormith, Paul Davidson, and Denise Preston for their insightful comments on an earlier draft of this thesis. And I also thank the inmates who volunteered their time as subjects.

Finally, and most importantly, I want to acknowledge the encouragement and support of my wife Wendy and daughter Kate. 
Control of Penile Tumescence

Table of Contents

Page

Abstract $\ldots \ldots \ldots \ldots \ldots \ldots \ldots \ldots \ldots \ldots \ldots \ldots \ldots \ldots \ldots \ldots \ldots$

Acknowledgements........................... iv

Table of Contents $\ldots \ldots \ldots \ldots \ldots \ldots \ldots \ldots \ldots \ldots \ldots \ldots \ldots$

List of Tables............................. vii

List of figures............................ viii

Introduction. .............................

Measurement of Penile Tumescence............... 3

The Volumetric Method..................... 4

The Bioimpedance Method................... 4

The Ci rcumferential Method................. 4

Assumptions............................

Advantages and Disadvantages.................. 10

Research Rationale....................... 15

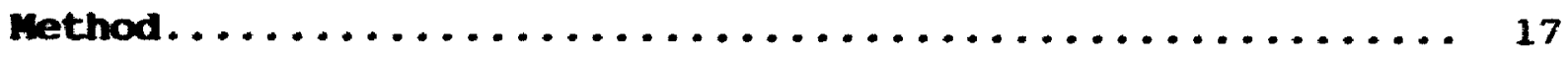

subjects................................ 17

Apparatus................................ 19

Penile Tumescence Recording ............... 19

Experimental setting..................... 21

stimuli............................ 21

Procedure................................... 22 
Control of Penile Tumescence

$\mathbf{v i}$

Table of contents

Page

Results............................... 28

Preliminary Analyses ................... 28

Experimental Analysis.................... 32

Discussion................................ 44

General Discussion....................... 50

Pootnotes................................ 53

Reference Notes............................

References................................ 55

Appendix A (Tanner Ratings) ....................60

Appendix B (Consent Form) .................... 61

Appendix C ( $\operatorname{Trial}$ orders) $\ldots \ldots \ldots \ldots \ldots \ldots \ldots \ldots \ldots \ldots \ldots \ldots$

Appendix D (Cvso Individual Data) ................ 63

Appendix E (Avso Individual Data) .................. 74 
Control of Penile Tumescence

vii

List of Tables

Table

Page

1 Sunmary of of fence Record Information

for Child Molesters . . . . . . . . . . . . . . . . 18

2 Sumary of offence Record Information

for Adult victin sex offenders............... 20

3 Category Preference Indices by Group . . . . . . . . . . . 43 
Control of Penile Tumescence

vi i i

list of Figures

Figure

Page

1 Time course of a single Trial ............... 24

2 Mean Tumescence Pre and Post Shift Averaged Acros:

Groups within stimulus Category ................ 29

3 Hean Tumescence During Subtrial 'Arouse' Averaged ithin Groups and within stinulus Categories ........... 31

4 Response Latency to 50 t During Subtrial 'Arouse' Averaged Within Groups and Between stimulus Categories ..... 33

5 Mean Tumescence Pre and Post Shift within stimulus Categories for the cvso Group ............... 35

6 Mean Tumescence Pre and Post Shift within stimulus Categories for the Avso Group ............... 36

7 Groups by stinulus Category Interaction ......... 38

8 Stinulus Category by Groups Subtrial "Control " ... . 39 
Control of Penile Tuescence

in Convicted Child Molesters:

Effects of a Mid-trial Change in stinulus content

In the past twenty years society has seen a growing recognition of sexual violence as a significant social and political problem. Increased awareness coupled with changes in police and court procedures have re:iulted in an increase of the reported incidence of sexual assault. However, it is still only a small proportion of the "estimated" actual incidence (Russel1, 1983).

This increased recognition has led to a substantial body of research devoted to describing and understanding behaviours which are associated with these reprehensible sexual acts. A majority of the research has been directed at issues of assessment, treatment and prevention. Ideally, research intends to attain a high level of predictive validity which would allow assessment of individuals and provide a probability that individuals in particular risk groups, have or will in the future, commit a deviant sexual act. Further, given these high risk individuals, it is important to be able to prescribe a treatment regime which will reduce the 1 ikelihood of re-offence. clearly issues of treatmint and prevention are to a large degree conditional 
Control of Penile Tumescence

on the accuracy of assessment. Without assessment procedures to identify those variables which contribute to deviant sexual behaviour, treatment and prevention seem premature.

Not surprisingly, attempts to understand deviant sexual behaviour have focused attention on men already identif icd as having committed a sexually deviant act. The intention here is to identify those factors which discriminate these offenders from non-offenders.

One area which has received considerable attention is the measurement of sexual arousal in accordance with the sexual preference hypothesis. According to this hypothesis, men commit sexually deviant acts because the activity is in some way rewarding and because other forms of sexual activity are not as rewarding. This concept or hypothesis has become widely accepted and usually forms the basis of a clinical assessment of sexual offenders. Indeed most of the classification systems for sexual offenders are based at least in part on the classification of sexual preferences. For example, DSH-III-R characterizes the paraphiliac as having sexual fantasies and arousal in response to sexual objects or behaviours that are not part of normative 
Control of Penile Tumescence

arousal-activity patterns (DSM-III-R) .

While a sexual preference is usually thought to be a stable trait within an individual, numerous treatment procedures have been developed to modify sexual preference. In fact, most recognized treatment programs for sexual offenders include as a major component the measurement and modification of sexual preference (Borzecki and Wormith, 1987). Typically in phallometric assessments, appropriate and inappropriate stimuli are presented to subjects while their sexual arousal (penile tumescence) is monitored. Increases in penile tumescence in the presence of inappropriate stimuli relative to that in the presence of appropriate stimuli are the usual measure of deviant sexual arousal (Davidson and Malcolm, 1985; Earls and Quinsey, 1985). Methods used in the calculation of these indices are still being debated (Harris, Quinsey and Rice, 1991). As well, Barbaree and Marshal1, (1989) have recommended the use of profile analysis with child molesters.

Heasurement of Penile Tumescence

There are currently three methods used to evaluate penile tumescence, volumetric, bioimpedance and circumferential. Each will be described in some detail. 
Control of Penile Tumescence

4

The Volumetric Method. This method of measuring penile tumescence measures the entire volume of change in the penis (Freund, Sedlacek, and Knob, 1965; McConaghy, 1967). The apparatus consists of an inflatable cuff which the subject places around the base of his penis, and a glass cylinder which encompasses both his penis and the cuff. The latter is inflated to produce an air-tight seal between the penis and the cylinder, which is closed except for a tube which carries displaced air to a pressure sensor. These devices are considered to be highly sensitive to minute changes, but are bulky, difficult to operate, and expensive.

The Bioinpedance Method. This method of estimating penile tumescence is based on the fact that skin decreases in electrical conductivity as it is stretched (Bradford, 1986). It's principle failing is that changes in galvanic skin response may confound the changes due to penile tumescence. Unfortunately, galvanic skin response has not been found to be a reliable measure of sexual arousal (Zuckerman, 1971: Quinsey, Steinman, Bergersen and Holmes, 1975) and to date, bioimpedance analysis has met with only limited acceptance.

The Circunferential Hethod. The circumferential method 
Control of Penile Tumescence

of plethysmograph estimates penile change by measuring changes in circumference (Bancroft, Jones, and Pullen, 1966; Barlow, Becker, Leitenberg, and Argas, 1970). There are two popular circumferential transducers. The first (Barlowtype) is an electro-mechanical strain gaige mounted on an expandable metal ring (Barlow et al., 1970). The second is a hollow tube of rubber filled with liquid mercury, known as mercury-in-rubber strain gauge (Bancroft, et al., 1966). These devices are considered not to be as sensitive to minute change as the volumetric devices but are relatively unobtrusive, easily applied, and inexpensive. In a study which compared the relative efficacy of the two circumferential transducers, Laws, (1977) found no significant differences. However, Laws recommended the mercury-in-rubber strain gauge due to its relative low cost and availability. In addition, several studies have examined the reliability and validity of the mercury gauges in terms of penile measurement. These studies found the device to be reliable, linear and resistant to temperature change (Davidson, Malcolm, Lanthier, Barbaree and Ho, 1981; Earls and Jackson, 1981; Farkas, Evans, Sine, Eifert, wittlieb, and Vogelmann-Sine, 1979). 
Control of Penile Tumescence

The actual operation of the mercury-in-rubber gauge is quite simple. When the tubing is stretched, the diameter of the liquid mercury within the tubing is reduced, this results in a diminished ability of the mercury to conduct an electrical current. The decrease in conductance is then transformed by a plethysmograph into a dc voltage output, which can be further transformed into digital or graphic output (Laws and Osbourne, 1983).

The simplest and certainly least expensive method of translating the voltage changes is to attach a digital voltameter to the plethysmograph and record voltage changes at prescribed intervals. While acceptable, this method requires the undivided attention of the experimenter and the identification of momentary spikes due to movement or other response artifacts is virtually impossible. A preferable method is to enlist the aid of a micro-computer to record and store the data as well as providing a graphical representation. In addition, the computer can be used to automate a variety of experimental events, decisions and calculations such as automated stimulus presentation, accurate inter-stimulus intervals and data transformations such as percent of full erection or z-scores. Thus the 
Control of Penile Tumescence

experimenter obtains a greater degree of experimental control during the assessment.

Assumptions. There are three basic assumptions which underlie the use of penile tumescence as a measure of sexual arousal. First, penile tumescence is the most direct and reliable measure of sexual arousal. Second, sexual arousal measured in the laboratory is related in some way to sexual behaviour exhibited outside the laboratory. And third, sexual arousal is predominantly beyond voluntary control. Although Masters and Johnson (1966) found there were a number of indices of sexual arousal in males, penile tumescence was generally found to be the first overt reference to occur in response to sexual stimulation. Wenger, Averill and Smith (1968) have argued that measures of penile erection are the only measures which reliably differentiate sexual arousal from other emotional states, such as anxiety and disgust. Subsequently, Zuckerman (1971) provided bench-mark support for the use of penile tumescence in the laboratory. Zuckerman's review included other measures of arousal such as cardiovascular change, skin temperature, pupillary dilation, average evoked cortical response, catecholamine excretions and penile erection. 
Control of Penile Tumescence

zuckerman concluded that penile tumescence was the single most reliable indicator of sexual arousal in males. Finally, Rosen and Keefe, (1978) concluded that "in the human male, measurement of the penile erectile response appears to be the only psychophysiological method which reliably discriminates sexual arousal from all other emotional states".

The second assumption relates to external validity or the extent by which measures of penile tumescence gathered in the laboratory relate to sexual behaviour outside the laboratory. From a psychometric point of view we are assuming that measured sexual arousal "state" is somehow related to an underlying "trait" and therefore is predictive of future behaviour. Discriminant validity, or the ability of a measured state to correctly discriminate between individuals with known traits has been the focus of considerable research in this area. Penile tumescence measures have been used successfully to discriminate a variety of anomalous sexual behaviours including: homosexuality (Freund, 1963): fetishism (Marks and Gelder, 1967); transvestism (Marks and Gelder, 1967); exhibitionism (Langevin, Paitich, Ramsey, Anderson, Pope, Pearl, and 
Control of Penile Tumescence

Newman, 1979): pedophilia (Quinsey, 1977); and sexual aggression (Abel, Barlow, Blanchard and Guild, 1977, Barbaree, Marshall and Lanthier, 1979).

The third assumption relates to the voluntary control of penile tumescence. Early human physiology text books considered the erectile response as predominantly a reflex (Houssay, 1955), and Masters and Johnson (1966) considered the penile erection as the male's first sexual response. However, more recent research has shown quite conclusively that some subjects can voluntarily produce or inhibit the erectile response (Freund, 1961, 1963; Henson and Rubin, 1971; Laws and Holmen, 1978; Laws and Rubin, 1969; Quinsey and Bergersen, 1976). Although there are methods of reducing the effects of voluntary control the mere fact that it is possible must be considered when interpreting penile tumescence data. This is less an issue when the results clearly indicate a preference in the direction of deviance, as it is unlikely that a subject would fake an inappropriate profile. However, when the result is borderline or indicative of a "normal" profile, three possible explanations must be considered: 1) the subject has a sexual preference which matches the displayed profile; 2) the 
Control of Penile Tumescence

subject has successfully controlled his responding, thereby presenting himself as having a less deviant profile; and 3) the sexual context of the stimulus set being presented is inappropriate for the subject (i.e. some subjects require a stimulus that is a combination of inappropriate cues). It is also important that the above explanations be considered when evaluating progress within the context of treatment as change from an inappropriate to an appropriate assessment protile following a course of treatment could be the result of an altered preference or simply an acquired control strategy. Nonetheless, voluntary control is a major threat to the internal validity and external validity of assessments using measures of penile tumescence.

Mdvantages and Disadvantages. The primary advantage of the direct measurement of penile tumescence is that it gives a reasonably precise estimate of sexual arousal using relatively inexpensive instrumentation with known operating characteristics. Consequently, it avoids an over reliance on self-reported sexual preference. Obviously, it is important to ask a subject about his sexual preferences and practices, however, this information must be considered with caution (Wormith, 1986). This is especially true when the 
Control of Penile Tumescence

results of the assessment may have a bearing on external events for an offender such as sentence length, parole, or supervision decisions. Clearly, these subjects have much to gain by presenting a non-deviant profile. In addition, objective measurement of penile tumescence allows clinicians and researchers to evaluate the effects of a variety of variables on sexual responsiveness. For example, there is evidence to suggest that the effects of alcohol can interfere with the ability of nonoffender males to differentiate consenting and nonconsenting stimuli (Barbaree, Marshall, Lightfoot, and Yates, 1983). This is also true for nonoffender males that have been recently angered by a female (Yates, Barbaree, Marshal1, 1983). Certainly the major disadvantage of plethysmographic measures of sexual preference relates to the aforementioned voluntary control of the erectile response. Clearly most offenders are able to suppress their erectile responses, at least to some degree (Abel, Barlow, Blanchard, and Mavissakalian, 1975; Freund, 1963, Malcolm, Davidson, Marshal1,1985), and some are able to produce moderate erectile responses to non-preferred stimuli (Quinsey and Bergensen, 1976). There is evidence of offenders faking by 
Control of Penile Tuncscence

using non-erectile responses such as altering blood flow to the penis by selectively tensing and relaxing the perineal muscles (pumping) or hyper-ventilation (Freund, Watson and Reinzo, 1988: Quinsey and Bergensen, 1976). Evidence also exists of subjects using mechanical methods of control, such as manipulating the strain gauge with a finger or a pencil (Laws and Holmen, 1978), and altering their attention to presented stimuli by averting their gaze or removing headphones (Laws and Rubin, 1969). There is no generally accepted method of controlling the possibility of faking. In the past it has been sufficient to racognize the problem of faking and to interpret assessment results with caution (Laws and Holman, 1978), or as Barlow (1977) suggests to arrange the testing environment such that the likelihood of faking is minimized. Some have focused on sophisticated techniques to detect which individual may be exercising control (Frenzel, 1990). One researcher suggested that a measure of each individual's ability to fake should be applied to the assessment and treatment results (Farkas. 1978 ).

An alternative strategy is to develop procedures which make the faking of a response either improbable or 
Control of Penile Tumescence

difficult. Certainly the most difficult type of faking to detect or combat is that which is under the subjects own cognitive control. According to freund (1988), these subjects achieve their goal by ignoring the relevant parts of the stimuli as much as possible and replacing them in imagery with stimuli which would normally suppress positive responses. To combat this form of faking, some authors have developed procedures which demand greater attention by the subject, thus forcing the subjects attention in the desired direction. Following procedures initially described by Laws and Rubin (1969) and Henson and Rubin (1971), Quinsey and Chaplin (1988) required normal volunteer subjects, while attending to an audio-taped stimulus, to press a button whenever sexual activity was being described and another when violence was described. They found that although subjects were able to fake inappropriate sexual preferences without the button pressing task, the task interfered with the ability to fake. Although this procedure obtained a certain degree of success in reducing the ability of nonoffender subjects to fake with audio-taped stimuli, it's use with slide transparencies used in assessments of age preference is not possible and it has yet to be tested with 
Control of Penile Tumescence

of fenders.

Following another hypothesis, Abel, Becker and skinner (1980) designed a study to detect inhibition in the presence of diverse stimuli in rapists and non-rapists. They showed that although nonrapists could inhibit equally well to both consenting and nonconsenting stimuli, rapists suppressed their arousal most effectively to consenting stimuli, thus increasing the ratio of rape-to-consenting arousal. They hypothesized that it is more difficult to inhibit in the presence of preferred than nonpreferred stimuli. However, in a similar study employing standardized stimuli, the results indicated that both groups of subjects inhibit equally well to both types of stimuli (Mydra, Marshall, Earls and Barbaree, 1983).

other researchers have employed procedures utilizing an abrupt stimulus shift to obviate response faking. In these procedures an appropriate stimulus is initially presented and then abruptly replaced with an inappropriate stimulus (Difranco, Malcolm, Baxter and Davidson, 1981; Freund, Chan and coulthard, 1979). Here the assumption is that it is more difficult to inhibit arousal after it has occurred and in the presence of a preferred stimulus. In an attempt to 
Contrci of Penile Tumescence

investigate this assumption Malcolm, Davidson and Marshall (1985), using non-child molester sex offender subjects, switched to various deviant and nondeviant stimuli after subjects had been aroused to different levels $(25,50$, and 758 of full erection). When the stimulus was switched, subjects were instructed to reduce their arousal as quickly as possible while attending to the switched stimulus. The results indicated that subjects had relatively more difficulty detumesing when presented with preferred stimuli compared with neutral and nonpreferred stimuli. Further, this difficulty was most apparent when subjects were aroused to approximately $50 \%$ of full erection when the switch occurred.

To date, no study has investigated this effect with child molester subjects, or presented an alternative method to counteract sexual preference response faking in child molester of fenders.

Research Rationale. The purpose of the present study was to investigate a method of reducing the effects of voluntary control during phallometric assessments of erotic age preference. The basic procedure follows those first described by Freund et al., (1979) and later eleporated on 
Control of Penile Tumescence

16

by Malcolm, et al., (1985). The procedure is one of using a mid-trial shift with instructions to inhibit ongoing arousal after the shift. The assumption is that voluntary control will be most difficult in the presence of a preferred stimulus and less difficult in the presence of a nonpreferred stimulus. Response latencies in detumesing to the deviant stimuli relative to the nondeviant stimuli will be taken as a measure of preference. Concurrent validity will be evaluated by correlating this measure of sexual preference with traditional measures of known discriminant and predictive validity. Further, the discriminant validity of this measure will be established by comparing subjects with established group membership. 
Control of Penile Tumescence

\section{Method}

\section{Subjects}

The subjects were adult males serving a sentence in a federal penitentiary. All subjects had been previously assessed between January 1, 1990 and May 31, 1992 at the Regional Treatment centre(0) to determine their suitability for a sexual of fender treatment program. Subjects were assigned to two groups based on their history of sexual of fending. The first group included 10 men convicted of a sex related offence against a female child less than 15 years of age. All subjects in this group had been administered an age gender preference assessment according to procedures described by Malcolm, Andrews and Quinsey, (1992). This group will be referred to as the child victim Sex offender group (CVSO). A summary of the convictions for each subject derived from criminal records, as well as subject age at offence, victim age, and child preference index', is presented in Table 1 .

The second group consisted of 10 men convicted of a sexual offence against a female greater than 18 years of age. This group will be referred to as the Adult victim Sex offender (AVSO) group (see Table 2). Further, the AVso group 


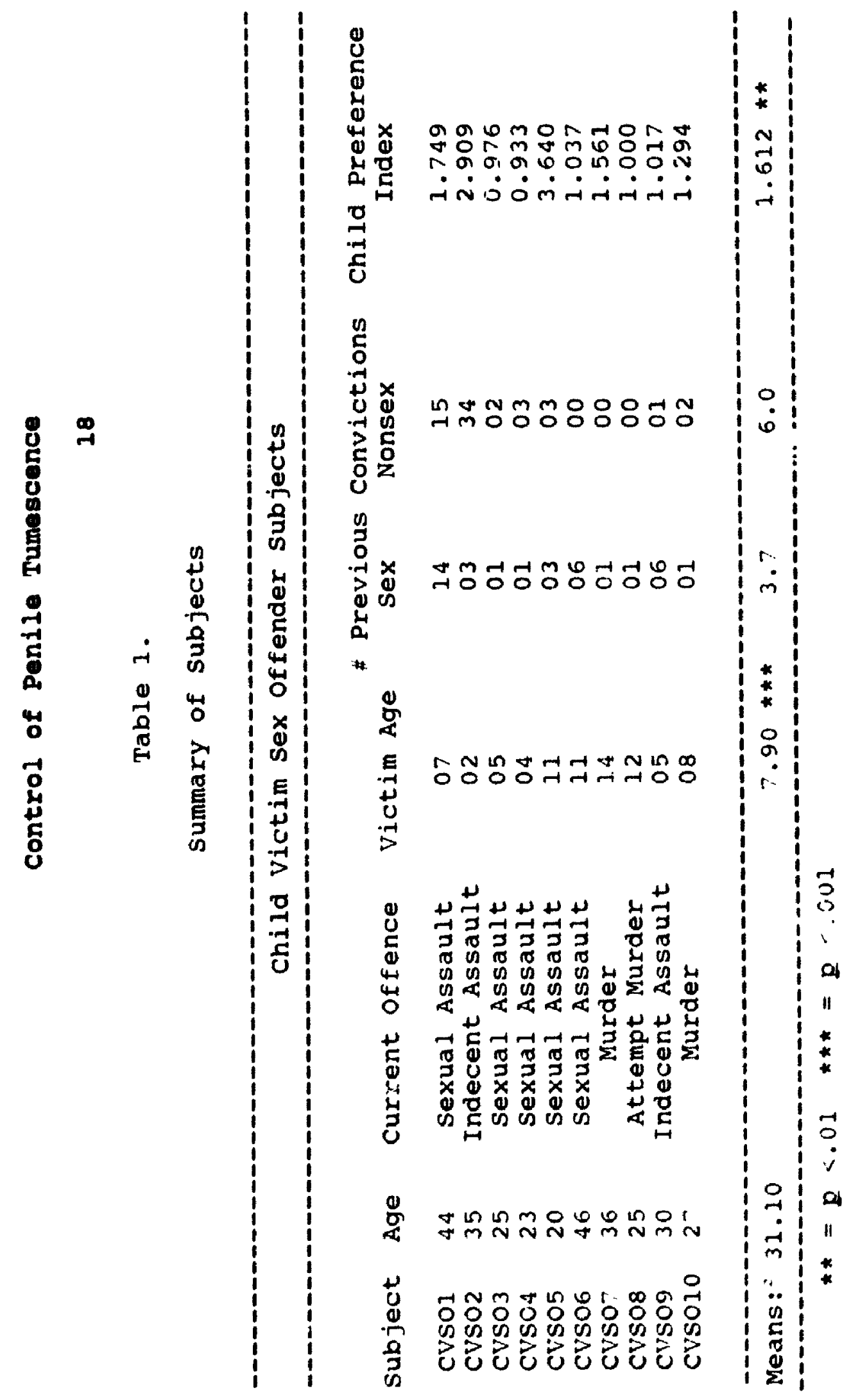


Control of Penile Tumescence

had a history free of any suggestion of sexual contact with children. Information regarding sexual history was gathered during a personal interview and a review of the subjects's criminal record as recorded by the Royal Canadian Mounted Police (R.C.M.P.). A summary of the convictions for each subject derived from criminal records, as well as subject age at offence, victim age, and child preference index ${ }^{1}$ is presented in Table 2 .

Apparatus

Penile tumescence recording. Penile tumescence was measured circumferentially using a mercury-in-rubber strain gauge (DM Davis Instruments). The gauge consisted of a thin column of mercury enclosed in a rubber ring which was placed midway up the shaft of the penis (Davidson, Malcolm, Lanthier, Barbaree and Ho, 1981). Changes in conductance in the mercury column of the gauge as a result of changes in penile circumference were transduced through a Parks model 270 plethysmograph (Parks Electronics). These data were collected on-line through a Hewlett-Packard model 2240 control processor 1 inked to a Hewlett-Packard series 9000 model 320 computer using software adapted for this study by the author. 


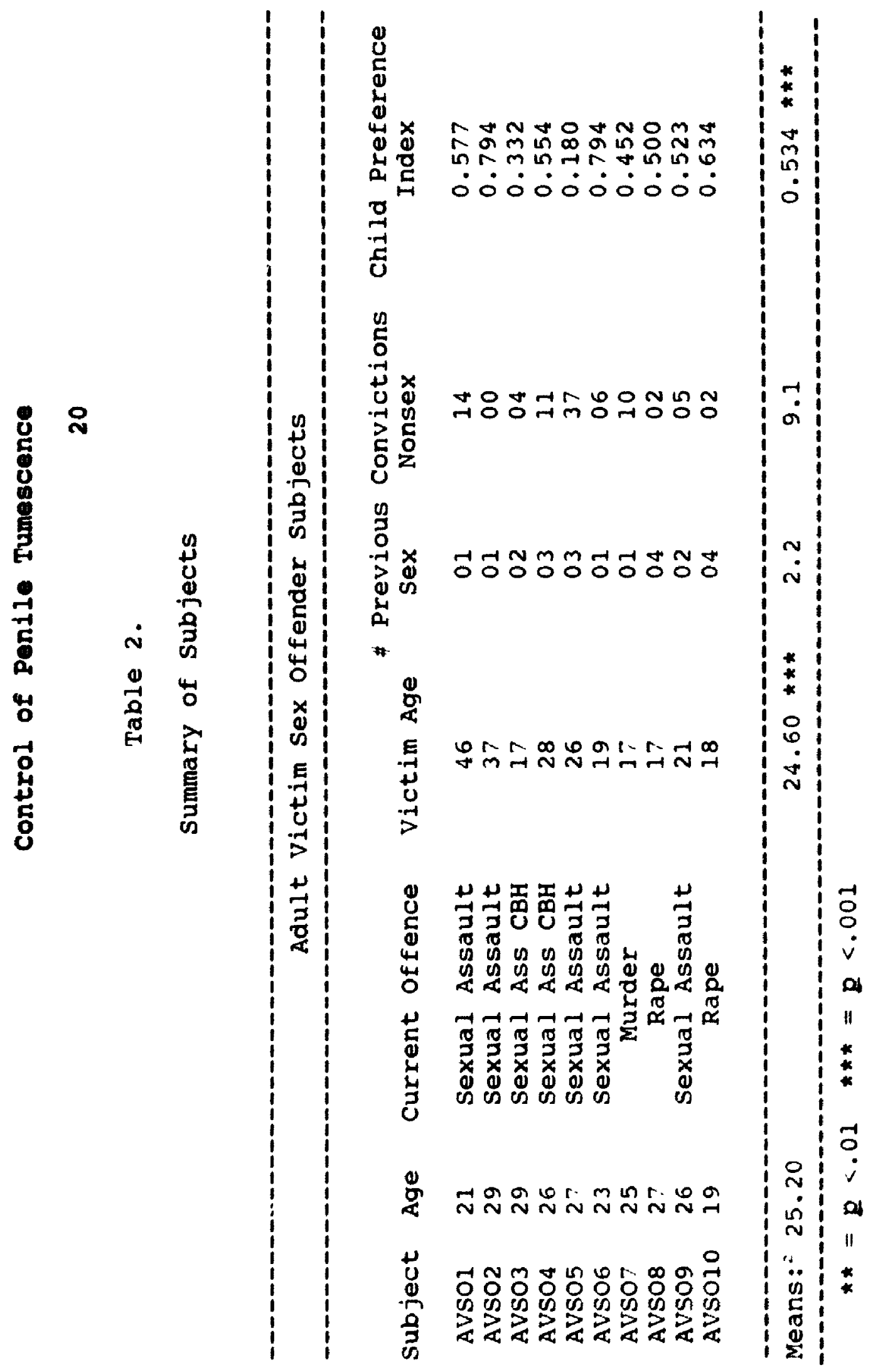


Control of Penile Tumescence

Experimental setting. Subjects reclined in a "lazyboy" style chair in a private sound-attenuated room while being monitored visually by a low-light surveillance video camera (Panasonic) to ensure their eyes were open and their gaze was in the appropriate direction. An intercom with closed headphones was used for continuous communication between the subject and the experimenter and to reduce external noise distractions.

stimuli. The assessment of age/gender preference employed two similar sets of slides-transparencies consisting of 8 nude female slides and 8 nude male transparencies. These transparencies were matched for explicitness of pose and age of model. Models were estimated to be aged approximately $5,8,10,12,15,18,22$, and 25 years.

Experimental stimuli consisted of 9 explicit video tapes portraying an adult male and adult female engaged in consenting sexual behaviour. A cursory attempt was made by the author to match the videos for sexual explicitness and appropriateness of content. In addition the experimental stimuli included 8 slide transparencies, 2 slides depicted a pictorial scene (Neutral), 2 slides depicted a nude adult 
Control of Penile Tumescence

female aged approximately 20-30 years (Adult Female), 2 slides depicted a nude pubescent female aged approximately 12-14 years (Pubescent Female), and 2 slides depicted a nude prepubescent female aged approximately 8-10 years (Prepubescent Female). The models in the slides were rated according to the Tanner system, which is a method of objectively rating physical maturation according to the presence of secondary sexual characteristics and overall body shape (Tanner, 1971). These ratings are presented as Appendix A. The video tapes were presented on a $20^{\prime \prime}$ colour TV screen (Sony Model, V02600). Slides were presented using a slide projector (Kodak Model, $860 \mathrm{H}$ ) with a zoom lens (Kodak Model Ektanar) onto a projection screen approximately $1 \mathrm{~m}^{2}$ and located $2 \mathrm{~m}$ in front of the subject.

\section{Procedure}

On initial contact subjects were given a complete description of the procedures to be used and an assurance of confidentiality. The option of declining participation in the experiment or withdrawing at any point during the experiment was explained prior to signing a form indicating informed consent. (Consent form attached as Appendix B). In an attempt to reduce the anxiety associated with this 
type of procedure, subjects toured the lab facilities and questions were answered without deception regarding the procedures and the purpose of the experiment.

The assessment of age/gender preference was administered during an assesment prior to these procedures. The models aged approximately 18 years of age were presented as warm-up stimuli. Each subject's Child Preference Index was calculated by dividing his average response to the female child slides ( 15 years of age and under) by the average response to the female adult slides. An index of greater than one indicates more of a response to the child slides than to the adult slides. The discriminant validity of these procedures and stimuli have been established and described, (Baxter, Marshall, Barbaree, Davidson and Malcolm, 1984; Malcoim, et al, 1991) and an estimate of predictive validity has also been reported (Malcolm, et al, 1991).

A total of eight stimulus trials were constructed. Each trial included one of 8 matched video tape scenes of sexually explicit material and one of the 8 slide transparencies from the four stimulus categories. Figure 1 presents the time course of events in a single trial. Each 
Control of Penile Tumescence

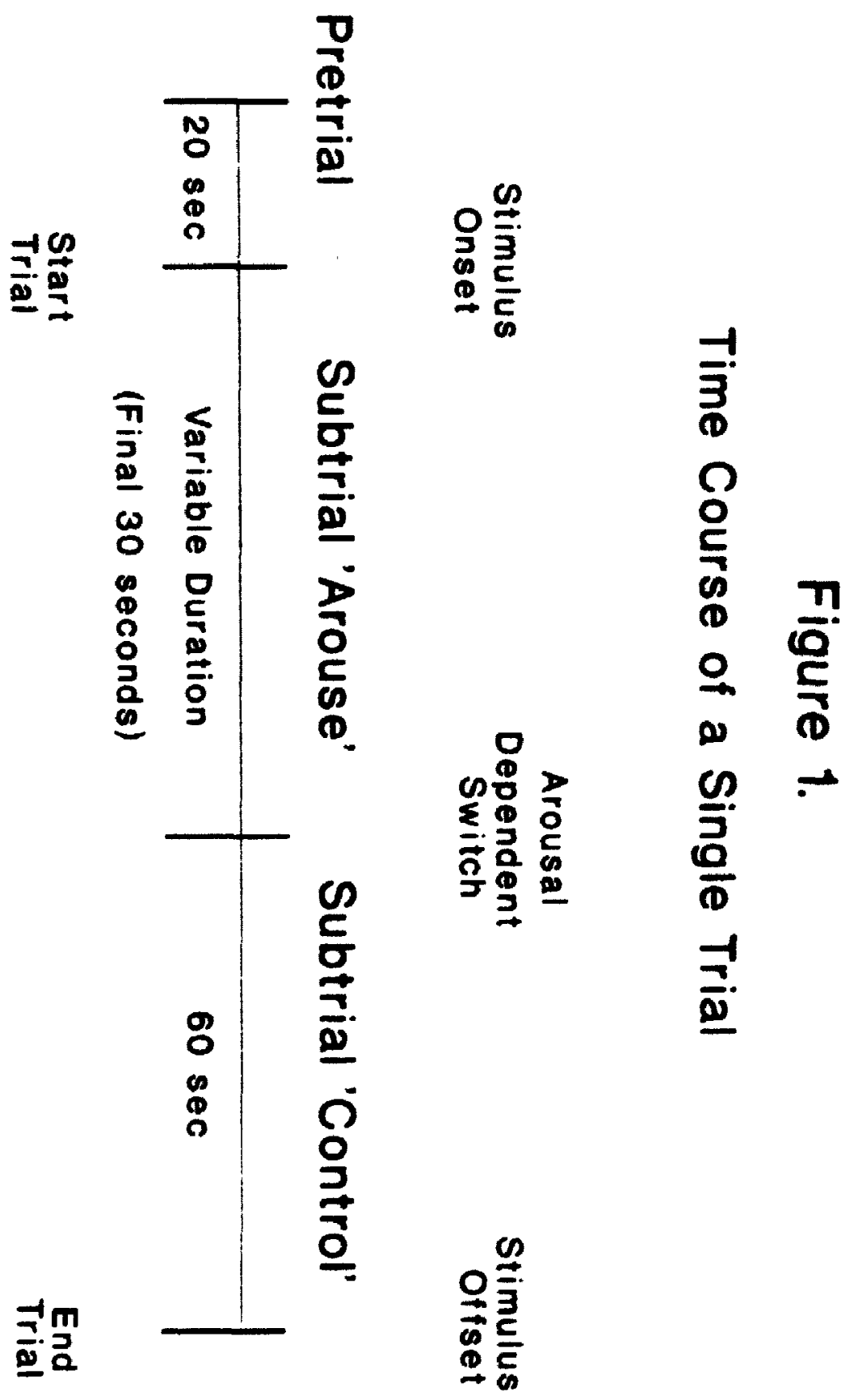


Control of Penile Tumescence

of the eight trial videos was presented until a predetermined level of arousal (50\%) was reached. This was labelled subtrial 'arouse' in Figure 1. When the required level of response was obtained the video was terminated (arousal dependent switch - Figure 1) and the slide was presented, labelled Subtrial 'control' in Figure 1, from one of the four stimulus category. The four stimulus categories presented during subtrial 'control' were: 1/ Neutral; 2/ Adult Female; 3/ Pubescent Female; and 4/ Prepubescent Female.

Penile tumescence data were sampled 1 time per second and then these data were averaged within 5 second intervals. Although, subtrial "arouse" was presented for a variable duration, penile tumescence was recorded for only the 30 seconds prior to the arousal dependent switch, to eliminate the effects of individual response latency while preserving the data of interest. Subtrial "control" was presented for 60 seconds and occurred immediately and sequentially when the precise switching level was reached. The interval between the offset of one trial and the onset of the next was approximately 1 minute. Subsequent trials did not begin until penile tumescence had returned to less than $5 \%$ of full 
Control of Penile Tumescence

erection, i.e. approximately a flaccid penis. The total session lasted approximately 45 minutes.

subjects were instructed in the proper procedure for fitting the strain gauge then the experimenter left the room while the subject fitted the gauge and became comfortable in the chair. Subjects sat with their pants and underpants lowered to mid-thigh and covered themselves from the waist down with a towel.

Each subject was presented a pre-trial explicit and consenting video tape and asked to allow himself to obtain a full erection. This erectile response was used to calculate voltage output at full erection and at 508 full erection to be used for switching the stimulus. Subjects were then given the following instructions:

I am about to present you with several pairs of a video tape followed by a slide. I am interested in the way in which you control your arousal during the slides. During the video tape $I$ would like you to allow yourself to become aroused; do not try to inhibit your arousal during this tape. When the tape stops and a slide appears it is your task to reduce your arousal as best you can, until 
Control of Penile Tumescence

you are no longer aroused. At all times you are to maintain eye contact with the slice being presented as this is an important part of the experiment. I will signal you when each video tape is about to begin. Do you understand what you are to do? Do you have any questions? The experiment will last approximately 45 minutes. sit back and relax and we shall begin.

The 8 trials followed these instructions. 10 different orders of presentation were constructed by randomly assigning 1 of the eight videos and 1 of the eight stimuli to each order. The only restriction placed on the orders ensured that a given stimulus category (Neutral, Adult Female, Pubescent Female, Prepubescent Female) did not follow one another. Une subject from each group was then randomly assigned to one of the ten orders. The content of these presentation orders is presented in Appendix $C$. 
Control of Penile Tumescence

\section{Results}

Penile tumescence was measured during al i phases of the study by calculating the difference in voltage output between the mean output of the plethysmograph at 5 -second intervals during stimulus presentations, and the output of the plethysmograph while the subject was at rest(flaccid). These values were then divided by the subjects range of responding (flaccid to full erection), and then multiplied by 100 to yield values representing percentage of full erection. All but one subject reported achieving a full erection (100\% penile tumescence) while viewing the initial pre-trial explicit video tape. This subject was released from continuing in the study and replaced with another. Tumescence data by stimulus category are presented in Figure 2. As can be seen from Figure 2, mean tumescence increased during the 'Arouse' subtrial to approximately $50 \%$. At that point the stimulus shift occurred, and arousal continued to increase briefly and then decreased during the 'control' subtrial. Prelininary Analysis.

Although data collected during the 'arouse' subtrials were not central to the issues being investigated in this 
Control of Penile Tumescence

(1) $000003 E-1$ d

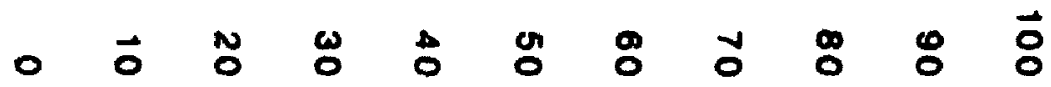

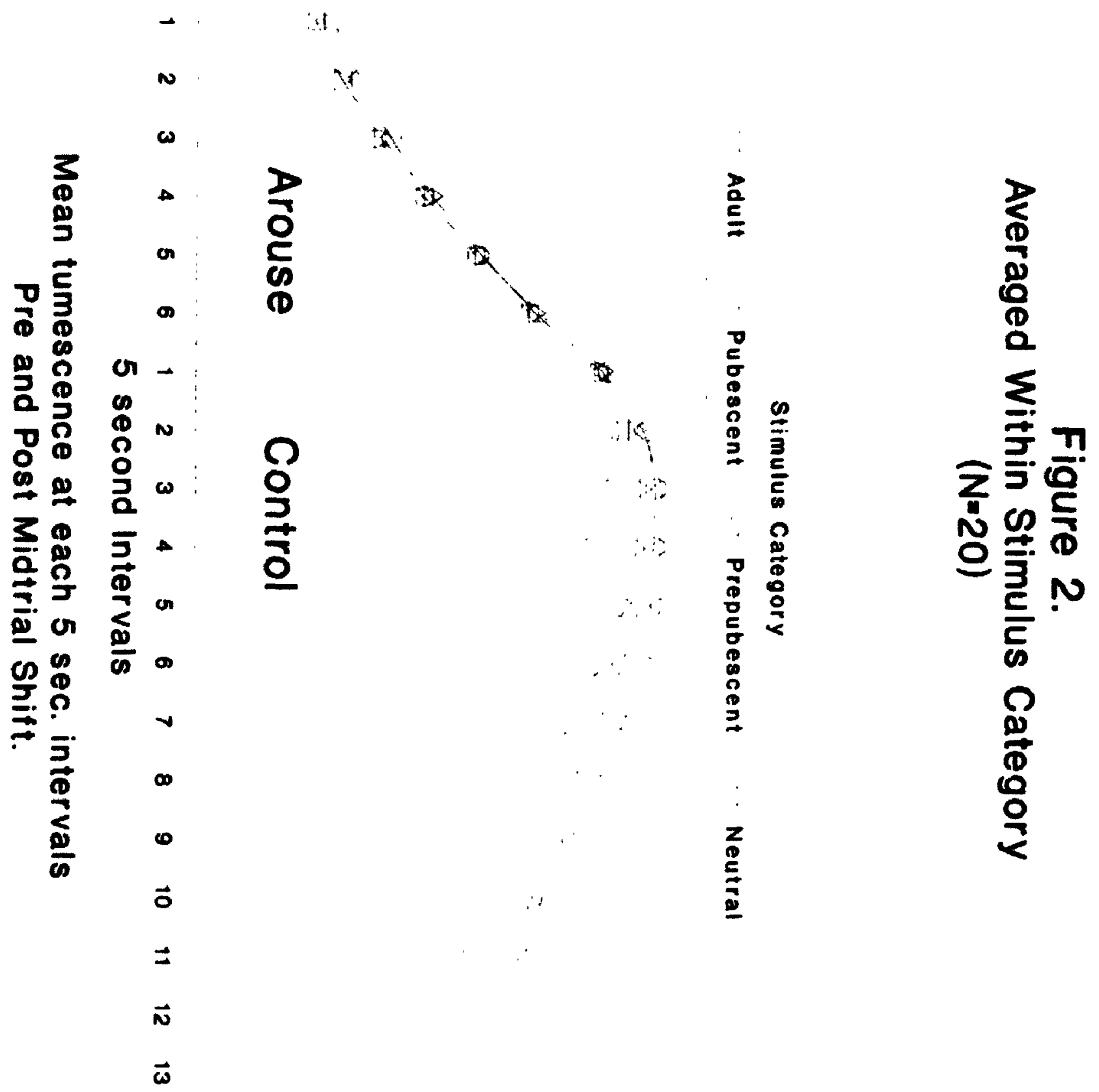


study, the 30 seconds immediately prior to the 'control' subtrial and the response latency to reaching $50 \%$ of full erection was analyzed to ensure equality $v_{i}$ arouse conditions. All subjects became aroused to the required level of $50 \%$ full erection during the 8 'arouse' subtrials. Figure 3 presents the mean tumescence response duriny subtrial 'arouse' for the two subject groups within the stimulus category for the trial.

A split plot analysis of variance was performed for mean tumsence during the 'arouse' subtrial comparing the four stimulus categories presented in subtrial 'control' and the two subject groups. This analysis was intended to determine the extent that responses during subtrial 'arouse' varied as a function of the stimulus category presented in subtrial 'control'. The results show no significant difference between the two groups $[F(1,152)=0.033,0, .10]$; the four slide categories $[F(3,152)=0.090, p>.10]$; or the groups by slide interaction $[F(3,152)=0.205, \mathrm{D} \times .10]$. The response time to reach the required $50 \%$ level of arousal was investigated to ensure that differences in subtrial 'control' were not due to differences in subtrial 'arouse'. Figure 4. presents the mean number of seconds; 
Control of Penile Tumescence

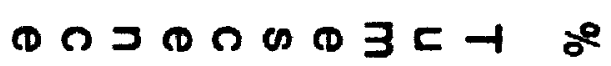

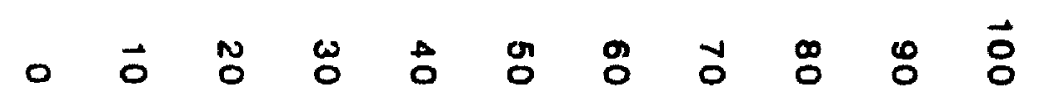

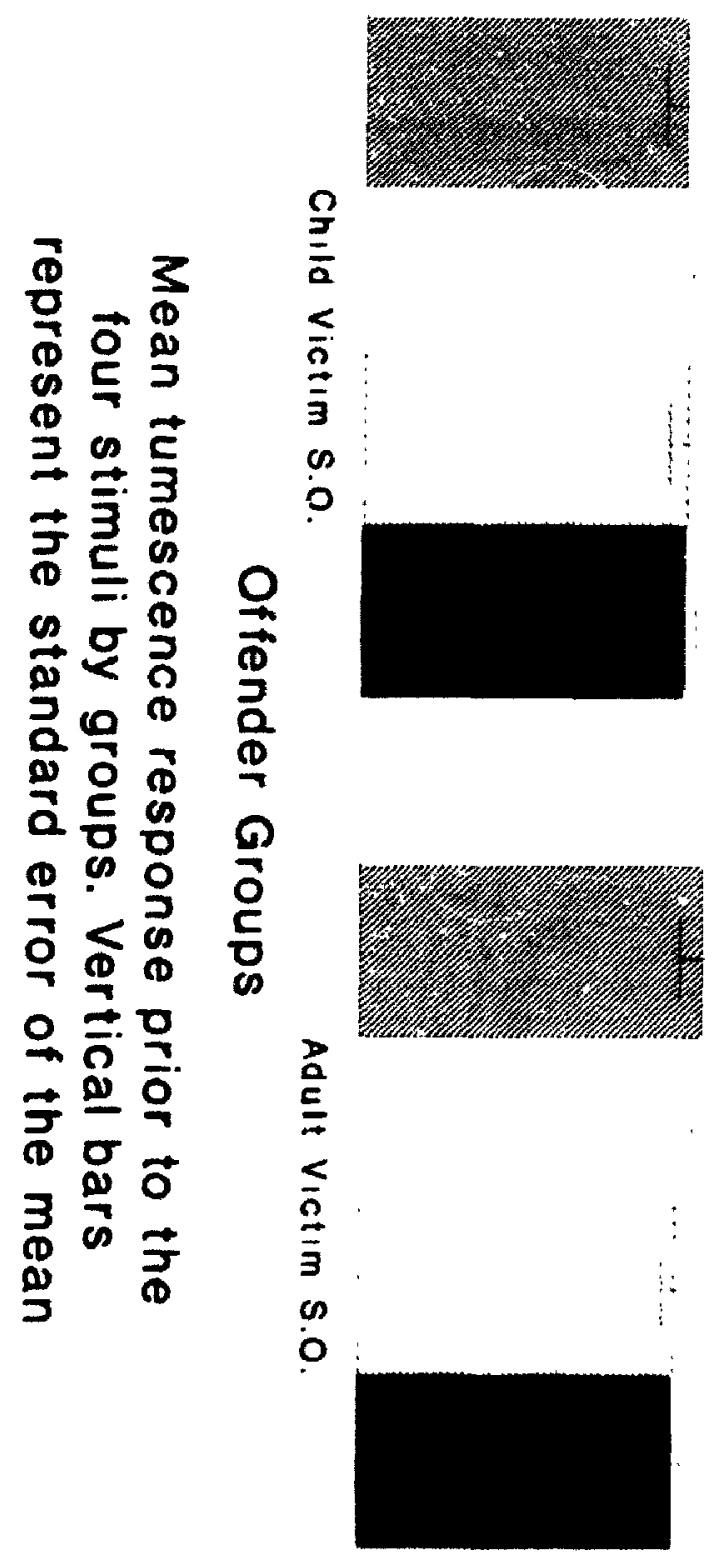

漗

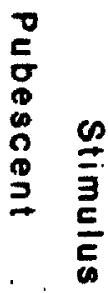

C

$\stackrel{5}{\rightarrow}+1$

ำ $\frac{5}{3} \overline{0}$

$\begin{array}{ll}\vdots & 8 \\ 0 & 0 \\ 0 & 0 \\ 0 & 0 \\ 0 & 0 \\ 0 & < \\ 0 & \\ 0 & \\ 0 & \\ 0 & \end{array}$

$=\infty$

$\geq \stackrel{0}{0}$

$\stackrel{\circ}{\partial} \omega$

क

Q

吾.

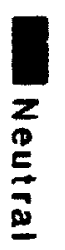


Control of Penile Tumescence

required to reach $50 \%$ of full erection relative to the stimulus category for the two subject groups.

A split plot analysis of variance was performed on the response latency data comparing stimulus category and groups. The results indicate that the child victim sex offenders took significantly more time to reach the required level of arousal than the Adult victim Sex offenders $[F(1,152)=7.245, \underline{p}<.01]$. However, differences were not found to be significantly related to the content of slides $[F(3,152)=0.783, \underline{p}>.10] ;$ and the groups by slide interaction did not reach statistical significance $[F(3,152)=0.783, \underline{2}>10]$

Finally, the 8 video tapes presented in subtrial 'arouse' were compared to ensure their equality of ability to arouse. The results indicate no difference in mean arousal across the 8 videos $[F(7,152)=0.100, p>.10]$ and no difference in latency to $50 \%[F(7,152)=0.325, \mathrm{p}>.10]$ for the 8 videos.

Experimental Analyses.

The data submitted for final analysis consisted of the mean tumescence response during each of the twelve 5 second intervals averaged over the four slide categories for the 
Control of Penile Tumescence \%OG $0 \rightarrow<0 D 0 \rightarrow \infty \Gamma$

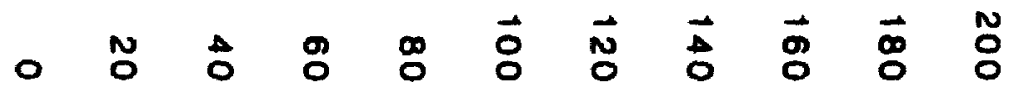

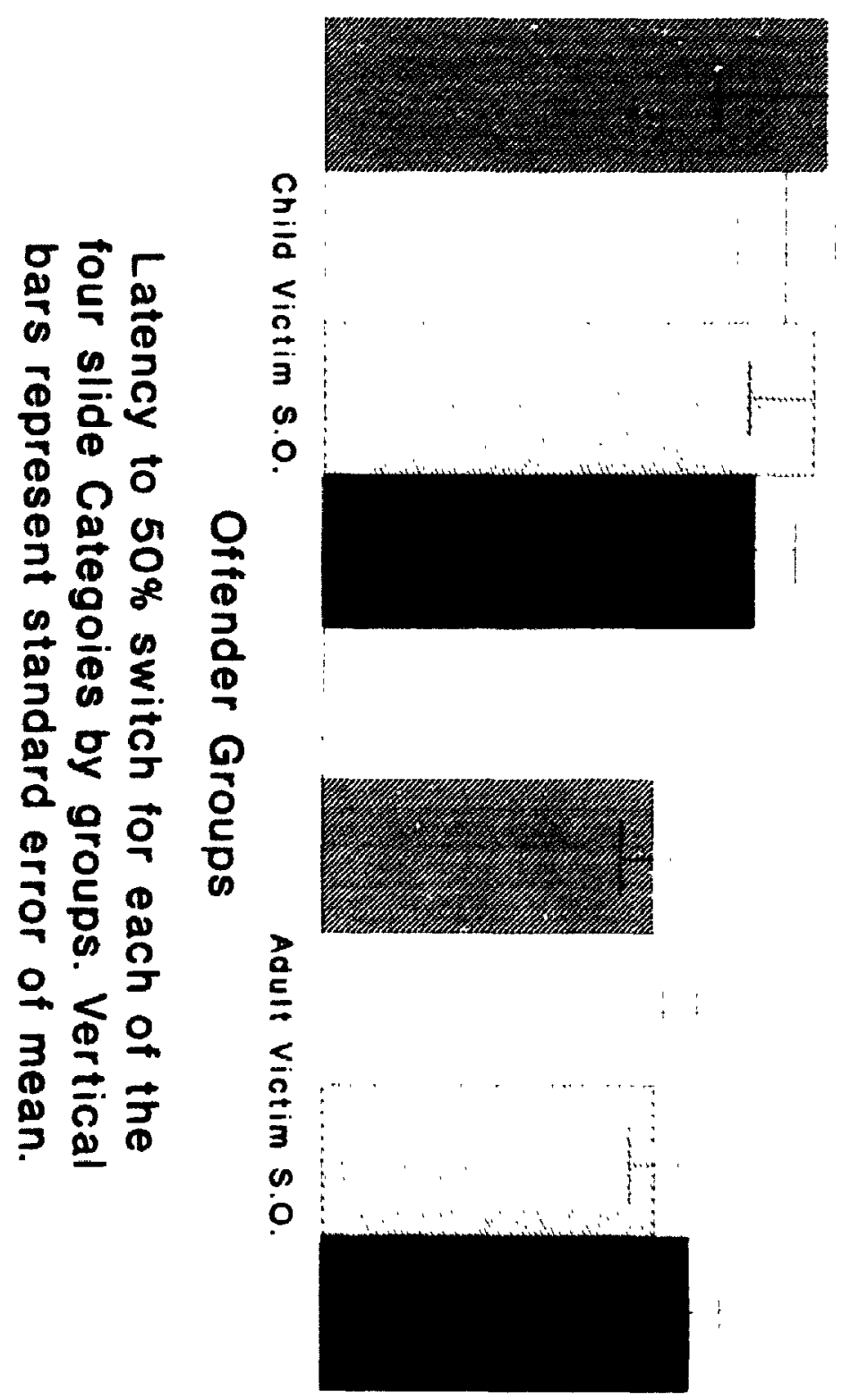

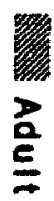
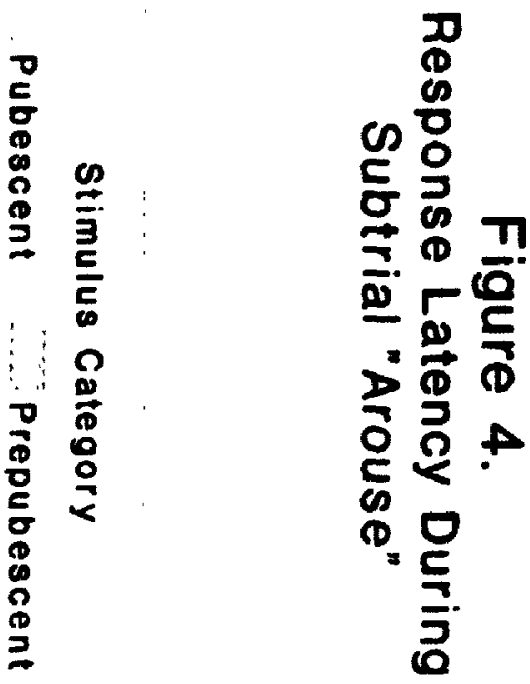


\section{Control of Penile Tumescence}

CVSO and AVSO groups. These data averaged within slide categories are presented in Figure 5 for the cVso group and Figure 6 for the AVSO group. Individual data for the cvso and AVSO groups are presented in Appendix D and E respectively.

A split plot analysis of variance was applied to mean tumescence response averaged over the 12 intervals. The two subject groups were the between subject factor and four stimulus categories as the within subject factor. As can be seen from Figure 7 , there was a significant groups-bystimulus category interaction $[F(3,54)=21.892, \underline{p}<.0 n 1]$. The two groups did not differ significantly in their ability to detumese during subtrial 'control' $[F(1,18)=0.262$, p>.10]. However, collapsing across the two groups, subject's ability to detumese was found to be significantly related to stimulus category $\left[F(3,54)=26.051, p^{<.001]}\right.$.

In order to evaluate the groups-by-stimulus category interaction, simple effect comparisons between the two groups for each of the four stimulus categories were performed. These results indicate that the AVSO group had greater difficulty relative to the cvso group detumesing in the presence of the adult female slides $[F(1,18)=5.367$, 
Control of Penile Tumescence (1) 0 D $0 \cos 3<-$ क

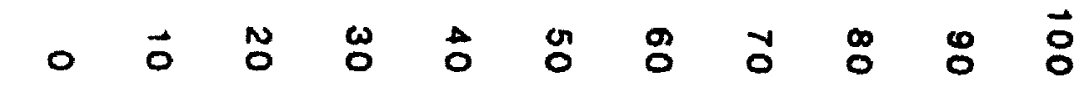

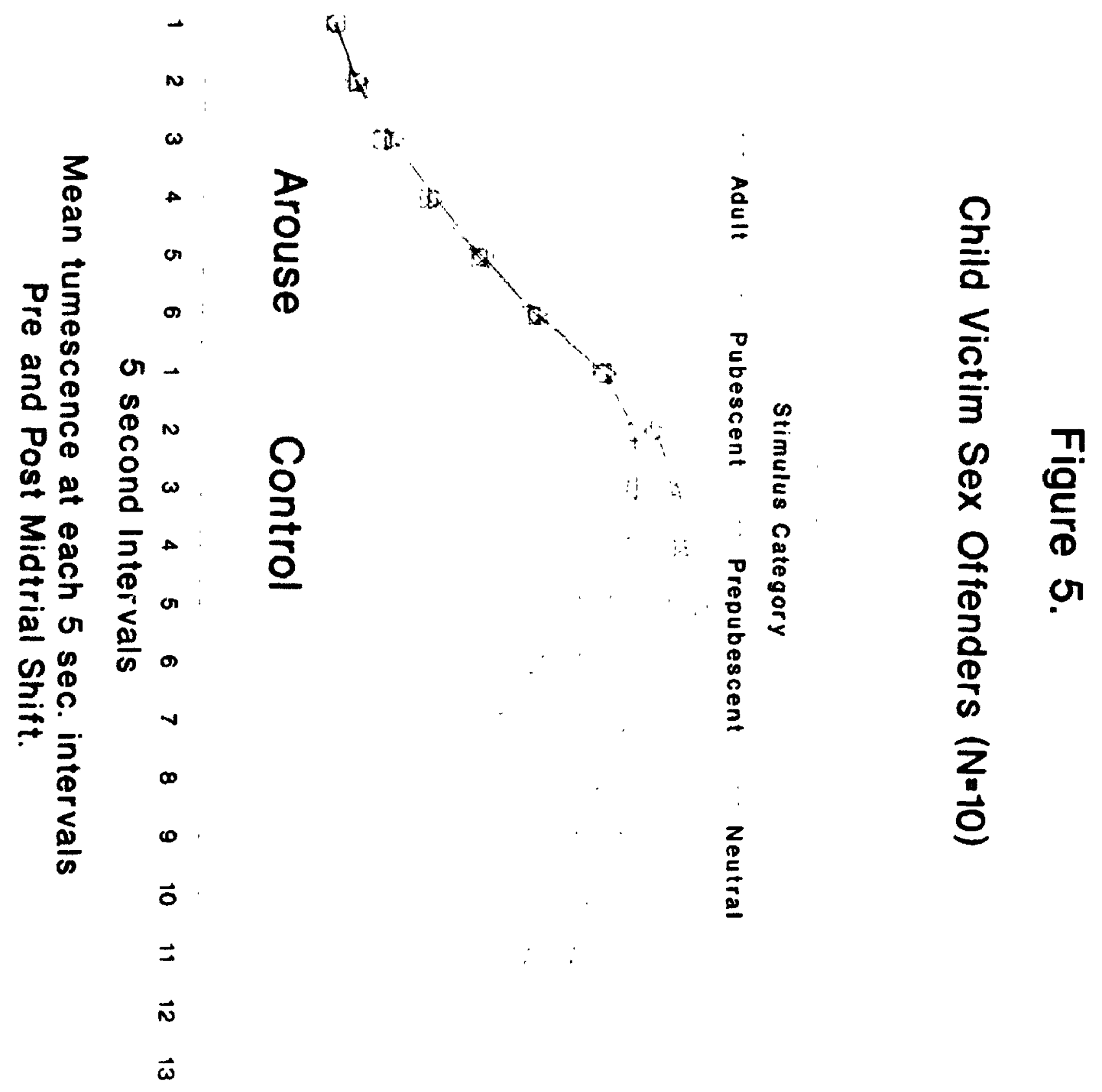




\section{Control of Penile Tumescence}

$\cos 0 \cos 3<-1$ o

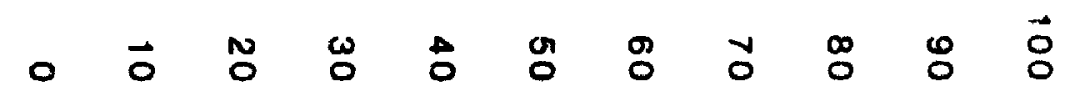

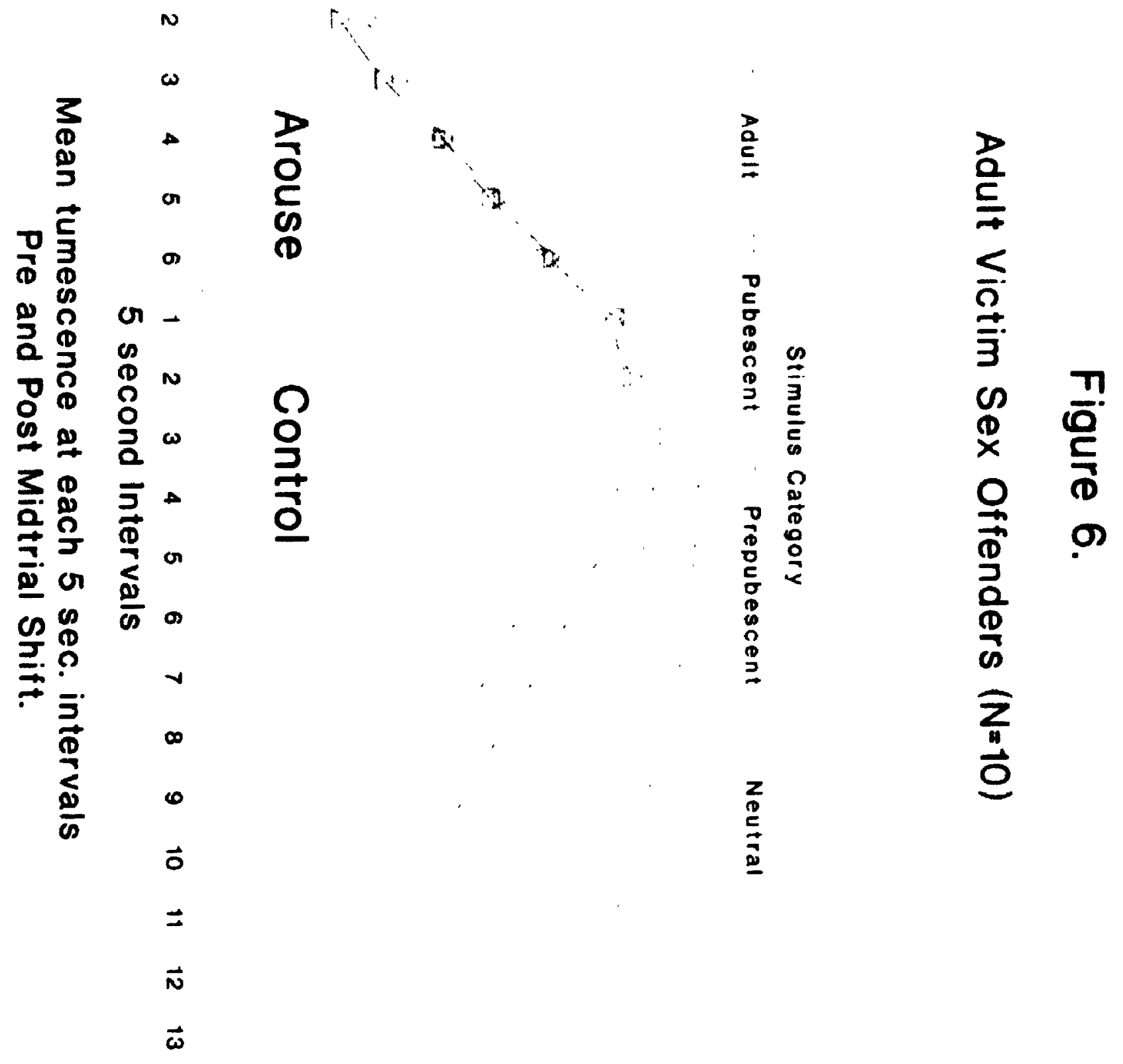


Control of Penile Tumescence

2\%.05]. Conversely, the cvso group had greater difficulty relative to the AVSo group detumesing while being presented the prepubescent female slides $[F(1,18)=5.095, p<.05]$. However, the two groups did not differ in the ability to detumese in the presence of the pubescent female slides $[F(1,18)=2.664, p>.10]$ or the Neutral slides $[F(1,18)=$ $0.355,2>.10]$.

The effect of stimulus category on the ability to detumese was evaluated within each subject group. This was found to vary significantly within the cvso group $[F(3,2 \%)=$ $15.031, p<.001]$ and within the AVSO group $[F(3,27)=43.368$, $\mathrm{Q}<.001]$. To further evaluate this effect three planned orthogonal comparisons were applied to these data. The first, compared the effect of presenting the neutral category with the combined effects of the adult, pubescent and prepubescent categories. This comparison was meant to reveal the effects of sexual versus non-sexual content, of the stimulus being presented on the ability to detumese, and was found to be significant in both the cVso $[F(1,9)=$ $20.613, p<.001]$ and the AVSo group $[F(1,9)=68.535$, $\mathfrak{p}<.001]$. The second comparison pitted the presentation of the adult category against the combined pubescent and the 

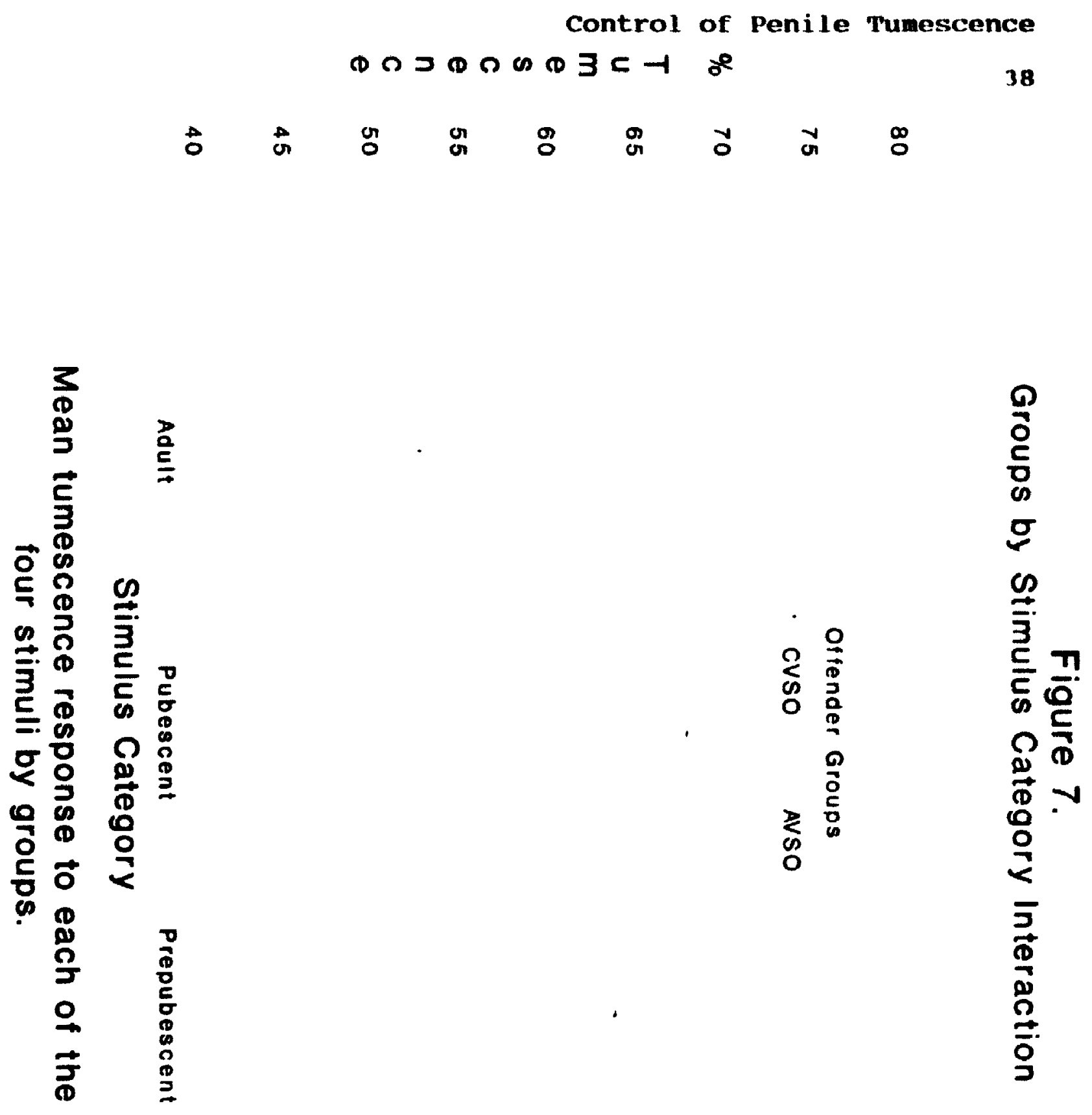


\section{Control of Penile Tumescence}

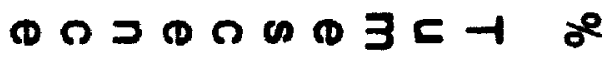

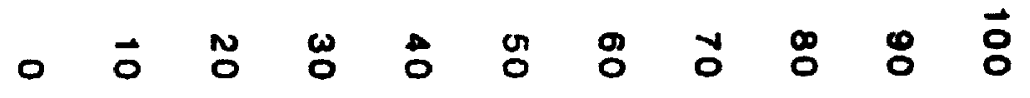

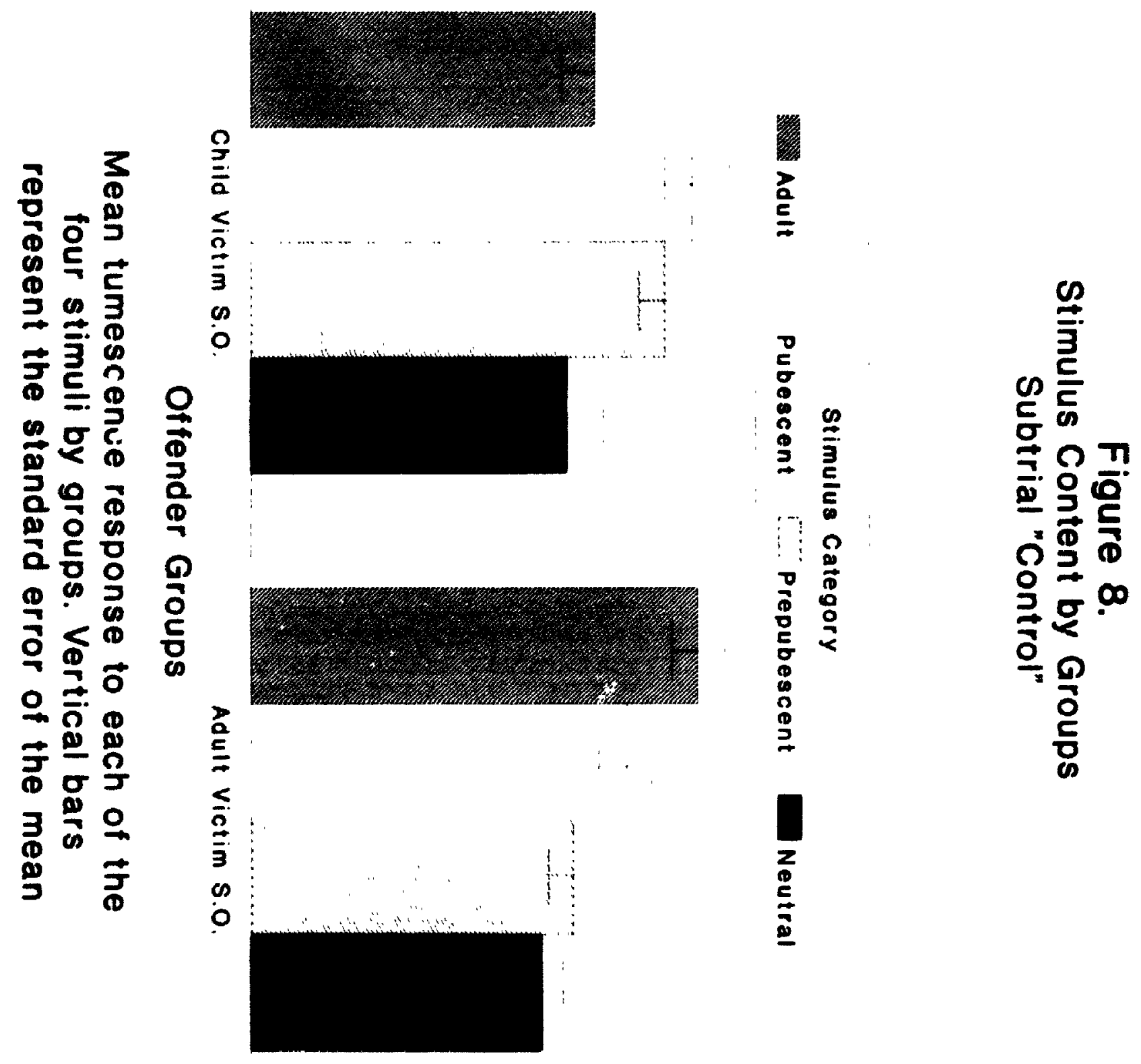


Control of Penile Tumescence

prepubescent categories. This comparison was intended to revealed the effects of appropriate versus inappropriate sexual stimuli and was also statistically significant for both the cVSo $[F(1,9)=30.571, \underline{p}<.001]$ and the AVso groups $[F(1,9)=131.045, \underline{p}<.001]$. However, average tumescence was greatest during the child categories for the cvso group and during the adult category for the AVSo group. The final comparison compared the presentation of the pubescent category with the prepubescent category. This comparison was meant to determine the sensitivity within the inappropriate categories and was found not to reach statistical significance $[F(1,9)=1.349, p>.10]$ for the CVSo group. However, this comparison was found to be statistically significant for the AVso group $[F(1,9)=$ $7.858,2<.02]$.

Finally, post hoc comparisons were conputed to determine if arousal inhibition during the presentation of the adult category was significantly different. from the presentation of the pubescent category. The critical value of $F$ was adjusted, and alpha was set at $p<.01$. This comparison was intended to test the sensitivity of the appropriate versus the inappropriate effect in greater 
Control of Penile Tumescence

detail. It was found to reach an acceptable levels of significance for the cVso group $[F(1,9)=16.291, \mathfrak{2}<.005]$, with arousal being greater during the pubescent category than for the adult category. This comparison was also significant for the AVSo group $[F(1,9)=69.896, \mathbb{2}<.001]$, but arousal was greater during the adult category.

Finally, an index to determine preferred stimulus cateyory was calculated for each subject. The index (Category Preference Index) was calculated by dividing mean arousal to the two inappropriate aged categories by the mean arousal to the appropriate aged category. As such indices of less than 1 would indicate a preference for adult categories while indices of greater than 1 would indicate a preference for inappropriate aged categories.

The two subject groups were compared relative to this index of category preference (see Table 3). The results indicated that the CVSo group was aroused significantly more to an inappropriate category (pubescent or prepubescent) versus the appropriate category (adult) than was the Avso group $[F(1,18)=38.196, Q<.001]$.

In addition, a Pearson Product Moment Correlation was calculated between the child preference index (based on the 


\section{Control of Penile Tumescence}

42

standard age/gender assessment) and the category preference index. This was found to be statistically significant $[x=.731,2<.001]$ 

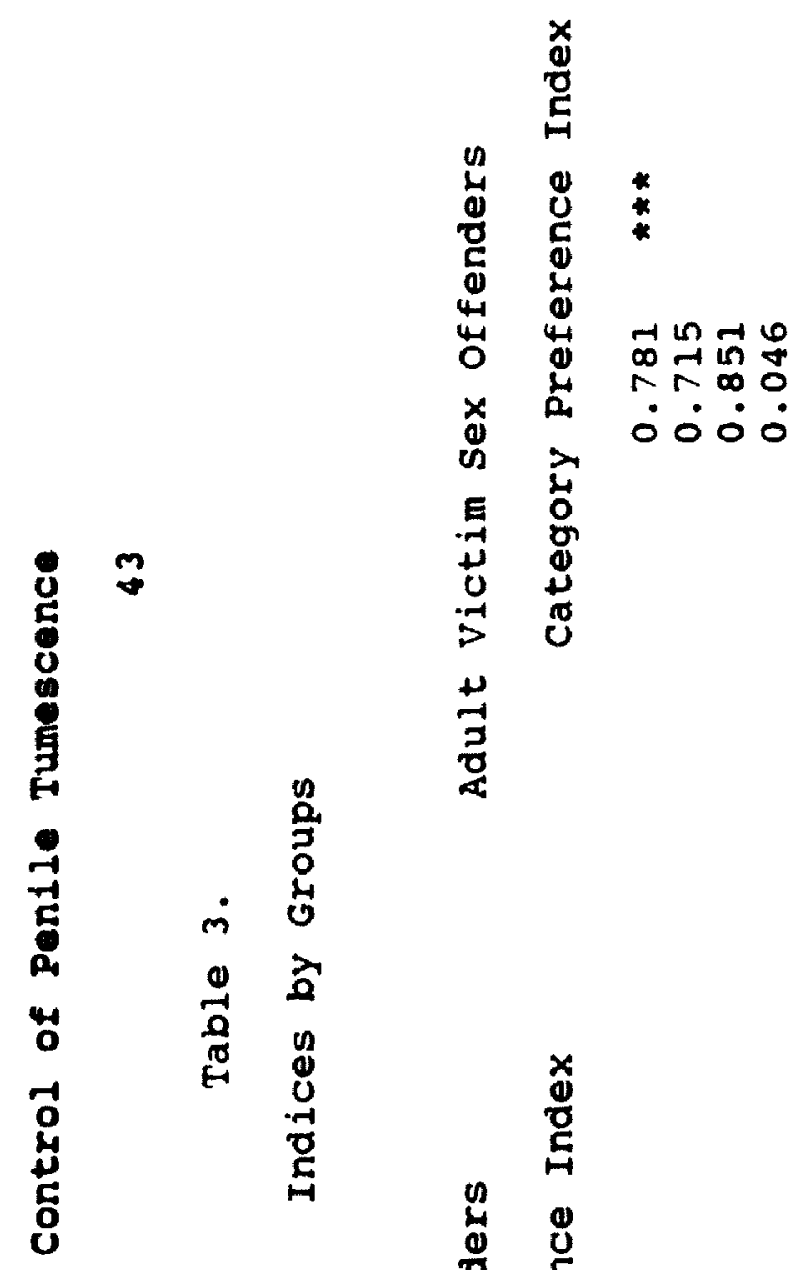

+1
0

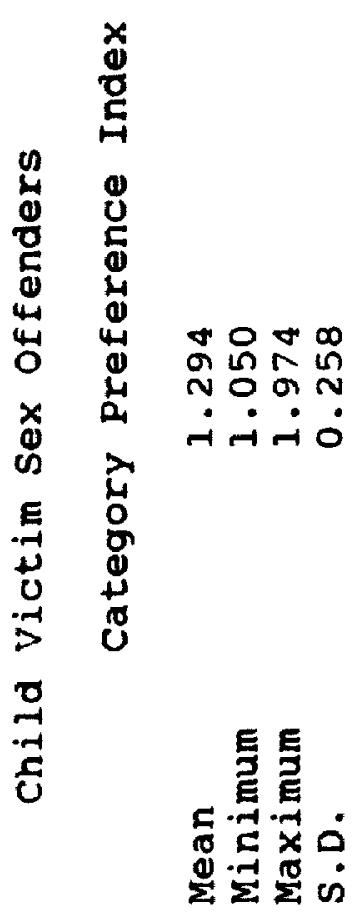


Control of Penile Tumescence

\section{Discussion}

The results of the present study indicate that the ability to suppress ongoing arousal is dependent upon the content of the stimulus being presented. It was found that when the stimulus being presented matched the subject's preference, the subject had greater difficulty in reducing arousal than if the stimulus was non-preferred.

The results of previous studies investigating the effects of stimulus content on the ability to suppress arousal have had varied results. According to Abel, et al,(1980) normals and rapists are best differentiated by deviant arousal under inhibit instructions. Conversely, Wydra, et al,(1983) state that both normals and rapists inhibit equally well to both types of stimuli. Finally, Malcolm, et a1,(1985), suggest that subjects can suppress equally well in presence of preferred and non-preferred stimuli when the instruction to do so is given prior to arousal occurring. However, these authors found that when subjects were pre-aroused to approximately $50 \%$ of full erection the ability to detumese was dependent upon the content of stimulus being viewed.

In the present study the ability to inhibit arousal, at 
Control of Penile Tumescence

approximately 50 of of full erection, while viewing a preferred, non-preferred and neutral stimuli was examined for two groups of subjects with markedly different sexual age preferences.

Subjects became sexually aroused to approximately 50\% of a full erection while viewing explicit consenting heterosexual video-tapes. A comparison of both the mean response during the thirty seconds priur to the 'control" subtrials and the latency to reach $50 \%$ of full erection indicated that these videos did not differ significantly in their ability to arouse subjects. As well, arousal levels prior to the presentation of the experimental stimuli were not found to vary in a significant manner relative to stimulus category. The AVso group's latency in reaching $50 \%$ full erection was significantly quicker than the cVso group. This is likely attributable to the videos presented involving adult females rather than child females. Given that the CVSO group has a measured preference for child females this is neither surprising nor important to the overall findings of this study. Nonetheless, it is an interesting finding in terms of the potential use of response latency as a measure of preference. 


\section{Control of Penile Tumescence}

From these analyses it is clear that no difference was identified in the 'arouse' subtrials relative to the stimulus categories to be presented in subtrial 'control'. We can then assume that differences found during the 'control' portion of the trials are attributable to the conditions found in the 'control' purtion and not the conditions in the 'arouse' portion.

clearly, the most important finding of the present study is that a subject's ability to inhibit ongoing sexual arousal at approxinately $50 \%$ of full erection is dependent on the content of the stimulus being viewed. The results clearly show that when sexual stimuli are presented, control over arousal is substantially weakened relative to when nonsexual stimuli are presented. In addition, when the sexual stimuli being presented are preferred, the ability to control arousal is hampered relative to when the sexual stimuli are non-preferred.

These observations have considerable relevance for the assessment of deviant sexual preference in those individuals for whom the validity of standard assessment measures are questionable. The results of most assessments of sexual preference are clear, and do not present difficulties in 
Control of Penile Tumescence

interpretation. However, for those cases that do present questionable results, employing a proced ure similar to that described here may be valuable. These data incicate that despite their best efforts, subjects are less able to reduce arousal in the presence of preferred rather than nonFreferred stimuli. This is not io say that subjects were uriable to exert control over their sexual arousal when presented a preferred sexual stimulus. However, the degree of control was reduced relative to that when ' $c$ non-preferred sexual stimulus was viewed. It would thus appear that comparing the ability of subjects to attenuate arousal in the presence of appropriate and inappropriate stimuli once approximately $50 \%$ of full erection has been generated, can be taken as a measure of the subjects sexual preference. This assumption is further supported in that standard child preference indices were significantly correlated with the new suppress indices.

In summary, these data indicate that the ability to exert voluntary control over penile tumescence is not the simple all or none process implied by earlier studies (Freund, 1961, 1963 and Henson and Rubin, 1971). These data clearly indicate that the ability to inhibit ongoing arousal 


\section{Control of Penile Tumescence}

is dependent on the sexual preferences of the subject being assessed. Therefore, the development of assessment techniques which utilize a mid-trial shift, with instructions to suppress, may prove invaluable in identifying the sexual preferences of individuals who are motivated to deceive.

Procedures such as these have advantages over traditional techniques in that highly provocative but appropriate stimuli are employed. According to Marshall, Barbaree and Christophe (1984), 28\% of their subject pool had to be excluded due to low arousal. In a more recent study by Malcolm, Andrews and Quinsey (1992), 48? of the subjects produced phallometric results that could not be interpreted due to arousal less than $10 \%$ of full erection. In the present study only $5 \%$ of the subjects were unable to complete the experiment. While not conclusive the likelihood of uninterpretable results due to low arousal becomes somewhat less probable. However, when an uninterpretable result does occurs it can be viewed as potentially meaningful. Rather than simply considering the stimulus material as lacking provocativeness, this result may be indicative of a somewhat different problem such as 
Control of Penile Tumescence

impotence or the need for a compound stimulus. For example the subject may require the dimension of violence to be present for arousal to occur. Further, subjects will not be able to claim disgust at viewing inappropriate sexual material as the material presented, when arousal is to occur, will always be appropriate. However, when the inappropriate stimuli are presented the instructions to suppress remain in accordance with their own wishes in terms of presenting favourably. Fortunately, based on these results the ability to control sexual arousal under these conditions is impaired by sexual preference.

From the perspective of faking, these procedures require the child molester who is motivated to fake to become sexually aroused to what would usually be a nonpreferred stimulus. The subject wants to present himself in this manner to convince the experimenter of his "normal" sexual preferences. Once in this aroused state the instruction to inhibit arousal is given and again the faking subject must comply with the instructions to present himself favourably. The subject complies with the instructions because the ability to control sexual arousal is as desirable a characteristic as having an appropriate sexual 
Control of Penile Tumescence

preference. However, in attempting to present favourably with regard to the ability to control sexual arousal, the subject inadvertently reveals his true sexual preference.

There are three apparent methods of employing these teshniques. The first would be to use the procedures described in this study as an assessment and have each subject receive both the standard assessment of age preference and a mid-trial shift assessment of age preference. Alternatively, only those individuals with results using the standard procedures that are questionable would receive the mid-trial shift assessment procedures. Finally, a few mid-trial shift trials could be appended to the standard assessment procedures. Thus, all subjects could be evaluated using both techniques during the same session.

\section{General Discussion}

The approach discussed here will require considerable validation in terms of discriminant and predictive validity before widespread use is recommended. However, the possibility of developing a technique for the measurement of sexual preference that is fake-proof requires the consideration of certain ethical problems and theoretical 
Control of Penile Tumescence

concerns (Quinsey et al, 1988).

clearly, the vast majority of individuals currently using phallometric tests use them for reasons of scientific inquiry and/or clinical intervention. These individuals are well aware of the distinction between an analog measure of sexual preference and the multidimensional construct that is actually sexual preference. The primary ethical problem relates to the individuals that employ phallometric measures and most importantly how these individuals use the information. As Quinsey et al,(1988) has pointed out, the development of a fake-proof procedure increases the potential for this type of testing to be used in a more police-like fashion. Some will argue that phallometric results be admissible as evidence of sexual preference in cases of child molestation. In addition, individuals making dispositional decisions will undoubtably want increased access to this type of information in the name of public safety. While far from insurmountable, this issue needs to be considered with foresight rather than hindsight.

of course the possibility of a fake-proof phallometric assessment procedure has considerable theoretical impact. The major theoretical issue relates to treatment induced 


\section{Control of Penile Tumescence}

changes in sexual preference. Subjects that demonstrate changes in sexual preference following a course of treatment may have simply acquired the ability to control arousal in the presence of preferred stimuli. Therefore, their underlying sexual preference will remain unchanged. of course, the intent of the subject in this case is of paramount importance as it may only be significant why an individual chooses to exert this type of stimulus control. Nonetheless, if treatment induced changes in sexual preference are due to the same processes as faking, subjects should still present as having deviant sexual preferences using these procedures. It will then remain for long term treatment outcome studies to determine the significance of short term treatment effects. 
Control of Penile Tumescence

53

Footnotes

A child preference index was calculated according to procedures described by Malcolm, Andrews and Quinsey, (1992). The index was determined by dividing the average peak response to the female models under 15 years of age by the average peak response to the female models over 15 years of age.

- Probabilities reflect differences between the two subject groups represented in table 1 and table 2. 


\section{Control of Penile Tumescence}

\section{Reference Notes}

Difranco, M.D., Malcolm, P.B., Baxter, D.J., and Davidson, P.R. The assessment of deviant sexual arousal in rapists: Ef fects of an abrupt relevant stimulus shift. Paper presented at the Annual Canadian Psychological Conference, Toronto, 1981.

Malcolm, P.B. Discriminant and Predictive Validity of Phallometric Age Preference. Independent research Carleton University, August, 1991. 
Control of Penile Tumescence

55

\section{References}

Abel, G.G., Barlow, D.H., Blanchard, E.B., anä Guild, D. (1977). The components of rapists' sexual arousal. Archives of General Psychiatry, 34. 895-903.

Abel, G.G., Becker, J.V., and Skinner, L.S. (1980). Aggressive behaviour and set. Psychiatric clinics of North America. 3. 133-151.

Bancroft, J.H., Jones, H.G., and Pullen, B.R. (1966). A simple transducer for measuring penile erection with comments on its use in the treatment of sexual disorder. Behavioral Research and Therapy, 4, 239-241.

Barbaree, H.E. \& Marshall, W.L. (1988). Deviant sexual arousal, of fence history, and demographic variables as predictors of reoffense among child molesters. Behavioral sciences and the Law, 6. 267-280.

Barbaree, H.E., Marshall, W.L. and Lanthier (1979). Deviant sexual arousal in rapists. Behaviour Research and Theraoy, 17. 215-222.

Barbaree, H.E., Marshall, W.L., Yates, E., and Lightfoot, L.O. $(1982)$. Alcohol intoxication and deviant sexual arousal in male social drinkers. Behaviour Research and Therapy. 21. 365-373.

Barlow, D.H., Becker, R., Leitenberg, H., and Argas, W.S. (1970) A mechanical strain gauge for recording penile circumference change. Journal of Applied Behaviour Analysis, 3, 73-76.

Baxter, D.J., Marshall, W.L., Barbaree, H.E., Davidson, P.R., and Malcolm, P.B. (1984). Deviant sexual behaviour:

Differentiating sex offenders by criminal and personal history, psychometric measures, and sexual response. Criminal Justice and Behaviour, 11, 477-501.

Borzecki, M. and Wormith, J.S. (1987) A survey of treatment programmes for sex offenders in North imerica. Canadian Psychology 28, 30-37. 
Control of Penile Tumescence

56

Bradford, J.M.W. (1986) The use a bioimpedance analyzer in the measurement of sexual arousal in male sex deviants. Canadian Journal of Psychiatry 31, 44-47.

Davidson, P.R., and Malcolm, P.B. (1985) The reliability of the rape index: A rapist sample. Behavioral Assessment 7, 283292.

Davidson, P.R., Malcolm, P.B., Lanthier, R.D., Barbaree, H.E., and Ho, T.P. (1981). Penile response measurement: operating characteristics of Parks plethysmograph. Behavioral Assessment 3, 137-143.

Earls, C.M. and Jackscn, D.R. (1981) The effects of temperature on the mercury-in-rubber strain gauge. Behavioral Assessment, 3 , 145-149.

Earls, C.M., and Quinsey, V.L. (1985). What is to be done? Future research on the assessment and treatment of sex offenders. Behavioral Sciences and the Lawe 3(4), 377-390.

Farkas, G.M. Comments on Levin et al. and Rosen and Kopel: Internal and external validity issues. Journal of Clinical and Consulting Psychology, 46, 1515-1516.

Farkas, G.M., Evans, I.M., Sine, L.F., Eifert, G. , wittlieb, E., and Vogelmann-Sine, S.(1979) Reliability and Validity of the mercury-in-rubber strain gauge measure of penile circumference. Behaviour Therapy, 10, 555-561.

Freund, K. (1961) Laboratory differential diagnosis of homo- and heterosexuality - an experiment with faking. Review of crechoslovak Medicine, 7, 20-31.

Freund, K. (1963) A laboratory method for diagnosing predominance of homo- or hetero-erotic interest in the male. Behaviour Research and Therapy, 1, 85-93.

Freund, K. (1967) Erotic preference in pedophilia. Behavior Research and Therapy. 5, 209-228. 
Control of Penile Tumescence

Freund, K., Chan, S., and Coultard, R. (1977) Phallometric diagnosis with 'nonadmitters. Behaviour Research and Therapy, 17, 451-457.

Freund, K., Watson, R. \& Rienzo, D. (1988) Signs of faking in the phallometric test. Behaviour Research and Therapy, 26, 105112 .

Freund, K., Sedlacek, F., and Knob, K. (1965) A simple transducer for mechanical plethysmograph of the male genital. Journal of Experimental Analysis of Behaviour, 8 , 169-170.

Harris, G.T., Rice, M.E., Quinsey, V.L., Chaplin, T.C., \& Earls, C.M. (submitted). Maximizing the discriminant validity of phallometric assessment.

Henson, D.E., and Rubin, H.B. (1971) Voluntary control of eroticism. Journal of Applied Behaviour Analysis, 4. 37-44.

Houssay, B.S. (1955) Human physiology. New York: McGraw-Hill.

Langevin, R., Paitich, D., Ramsey, G., Anderson, C., Pope, S., Pearl, L., and Newman, S. (1979) Experimental studies of the etiology of genital exhibitionism. Archives of Sexual Behaviour, 8, 307-331.

Laws, D.R. (1977) A comparison of the measurement characteristics of two circumferential penile transducers. Archives of Sexual Behaviour, 6, 45-51.

Laws, D.R. and Holmen, M.L. (1978) Sexual response faking by pedophiles. Criminal Justice and Behaviour, 5, 343-356.

Laws, D.R. and Rubin, H.B. (1969) Instructional control of an autonomic sexual response. Journal of Applied Behaviour Analysis, 2, 93-99.

Laws, D.R. and Osbourne, C.A. (1983) How to build and operate a behavioral laboratory to evaluate and treat sexual deviance. In J.G. Greer and I. R. Stuart (Eds.), The sexual aggressor: Current perspectives on treatment. New York. Van Nostrand Rinhold. 


\section{Control of Penile Tumescence}

Malcolm, P.B., Davidson, P.R., and Marshall, W.L. (1985) control of penile tumescence: The effects of arousal level and stimulus content. and level of arousal. Behaviour Rescarch and Therapy, 23, 273-280.

Malcolm, P.B., Andrews, D.A. and Quınsey, V.I.. (submitted) Discriminant and predictive validity of phallometrically measured sexual age and gender preference.

Marks, I.M., and Gelder, J.L. (1967) Transvestism and fetishism: clinical and psychological changes during faradic aversion. British Journal of Psychiatry. 113. 711-729.

Masters, W.H., and Johnson, V.E. (1966) Human sexual response. soston: Little-Brown.

McCoraghy, N. (1967) Penile volume change to moving pictures of male and female nudes in heterosexual and homosexual males. Behaviour Research and Therapy, 5, 43-48.

Quinsey, V.L. (1977). The assessment and treatment of child molesters: A review. Canadian Psychological Review, 18 , 204-220.

Quinsey, V.L., and Bergersen, S.G. (1978). Instructional control of penile circumference in assessments of scxual preference. Behaviour Therapy, 7, 489-493.

Quinsey, V.L., Steinman, C.M., Bergersen, S.G., and Holmes, 'I'.F. (1975). Penile circumference, skin conductance, and ranking resporses of child molesters and "normals" to sexual and non-sexual visual stimuli. Behaviour Therapy, 6, 213-21\%.

Quinsey, V.L., and Chaplin, T.C. (1988). Preventing $t a k i n g$ in phallometric assessments of sexual preference. In R.A. Prentky and V.L. Quinsey (Eds.), Human sexual aggressision: Current perspectives. Annals of the New York Academy of Sciences, 528, 49-58.

Rosen, R.C. and Keefe, F.S. (1978) The measurement of human penile tumescence. Psychophysiology, 15, 366,-376,. 


\section{Control of Penile Tumescence}

Russe 11, D.E.H. (1983). Incidence and preva]ence of intratamilial and extrafamilial sexual abuse of female children. Child Abuse and Neglect, 2, 133-146.

Tanner, J.M. (1971) Sequence, tempo, and individual variation in the growth and development of boys and girls aged 12 to 16 . Daedalus, 100, 907-930.

Wenger, Averill and Smith (1968). Assessing dviant arousal: Physiological and cognitive aspects. Advances in Behaviour Research and Therapy, 8, 101-137.

Wormith, S.J. (1986). Assessing deviant arousal: Physiological and cognitive aspects. Advances in Behaviour Research and Therapy, 8, 101-137.

Wydra,A., Marshall, W.L., Earls, C.M., and Barbaree, H.E. (1983). Identification of cues and control of sexual arousal by rapists. Behaviour Research and Therapy, 21 . 469-476.

Yates, E., Barbaree, H.E., and Marshall, W.L. (1984). Anger and deviant sexual arousal. Behaviour Therapy, 15, 287-294.

Zuckerman, M. (1971) Physiological measures of sexual arousal in the human. Psychological Bulletin, 25, 297-327. 


\section{Control of Penile Tumescence}

Appendix $A$

Tanner Ratings

\section{slide Female Pubic Hair Stage}

501

502

503

504

505

506

507

508

5
5
3
3
1
1
Neutral
Neutral

\section{Female Breast} stage

5
5
3
3
1
1
Neutral
Neutral

\author{
Designation \\ Adult Female \\ Adult Female \\ Pubescent Female \\ Pubescent Female \\ Prebubescent Female \\ Prepubescent Female \\ Neutral \\ Neutral
}

Tanner Rating system

Female Pubic Hair

Stage 1. There is no pubic hair.

stage 2. There is sparse growth of long, slightly piqmemented, downy hair, straight or only slightly curled, primarily along the labia.

stage 3. The hair is considerably darker, coarser, and more curled. The hair spreads sparsely over the junction of the pubes.

stage 4. The hair, now adult in type, covers a smaller area than in the adult.

stage 5. The hair is adult in quantity and type.

Female Breasts

stage 1. The breasts are pre-adolescent. There is elevation of the papilla only.

Stage 2. Breast bud stage. A small mund is formed by the elevation of the breast and papilla. The areolar diameter enlarges.

Stage 3. There is further enlargement of the breats and areola with no separation of their contours.

Stage 4. There is projection of the areola and papilla to form a secondary mound above the level of the breast.

stage 5. The breasts resemble those of a mature female as; the areola has recessed to the general contour of the breast. 


\section{Control of Penile Tumescence}

61

Appendix $\mathrm{B}$

Consent Form

1

have volunteered to participate in an experiment specifically designed to study my sexual arousal. This consent and release is given freely and I affirm that I am not acting under fraud, duress, or menace of any person whomsoever.

While I view slide transparencies of nude people my sexual arousal will be measured by a small penile transducer, an apparatus which I will place around my penis while I am alone in the privacy of the laboratory. This device will only record changes in the circumference of my penis and cannot hurt me physically.

The overall results of this experiment will be communicated to me at the end of the experiment and I may be apprised of my own results in detail if I so request. I am assured of the confidentiality of the results of recording my sexual arousal and any information I have disclosed to the experimenters regarding any of my thoughts or behaviours. I hereby authorize the use of al1 records and personal data derived from these experiments for research purposes and publications provided there is no disclosure of the identity of the undersigned.

At any time during any stage of this experiment, I may voluntarily withdraw without penalty of any kind. Should I at any $t$ ime in this experiment become dissatisfied with my treatment, I understand that I am at liberty to take my complaints to the warden of Kingston Penitentiary and the Chairman of the Department of Psychology, Carleton University.

My signature below indicates that $I$ have read and understood all of the above and that I have all my questions concerning my participation in this experiment answered to my complete satisfaction. The signing of this document in no way affects my legal rights.

Siqned: Dated : 


\section{Control of Penile Tumescence}

\section{Appendix $C$}

Presentation orders

(each order will be presented three times, once to each group)

\footnotetext{
Sub\#01 |V1-505|V2-502|V3-508|V4-501|V5-503|V6-506|V7-507|V8-504|*

Sub\#02 |V5-501|V1-504|V4-508|V2-505|V3-502|V8-507|V7-506|V6-503|*

Sub\#03|V2-504|V6-501|V8-506|V4-502|V5-508|V3-505|V7-503|V1-507|*

Sub\#04|V1-506|V2-507|V8-503|V3-504|V7-501|V6-508|V4-5,05|Vs-502|*

Sub\#05|V7-508|V1-503|V5-505|V3-507|V2-506|V8-501|V4-504|V6-502|*

Sub\#06 |V1-501|V2-503|V4-507|V7-502|V6-505|V5-504|V8-508|V3-506|*

Sub\#07 |V8-502|V7-505|V6-504|V5-507|V4-506|V3-503|V2-501|V1-508|*

Sub\# $08|V 2-508| V 5-506|V 1-502| V s-503|V 6-507| V 7-504|V 8-505| V 3-501 \mid$ *

Sub\#09|V5-503|V3-508|V4-501|V6-506|V8-504|V7-507|V2-502|V1-505|*

Sub\#10|V8-507|V5-501|V2-505|V4-508|V1-504|V3-502|V6-503|V7-506|*
}

\section{Codes:}

$501=$ Adult Female slide 503=Pubescent Female Slide 505=Prepubescent Female Slide $507=$ Neutral Nature Scene Slide
502-Adult Female Slide $504=$ pubescent Female Side $506=$ Prepubescent female slide? 508=Neutral Nature scene slide

V1 to V8 = Sexually Explicit Mutually Consenting Adult Heterosexual Video Tapes 


\section{Control of Penile Tumescence}

63

Appendix D

CHILD MOLESTER GROUP INDIVIDUAL DATA 


\section{CVSO-1}

Averaged Within Stimulus Category

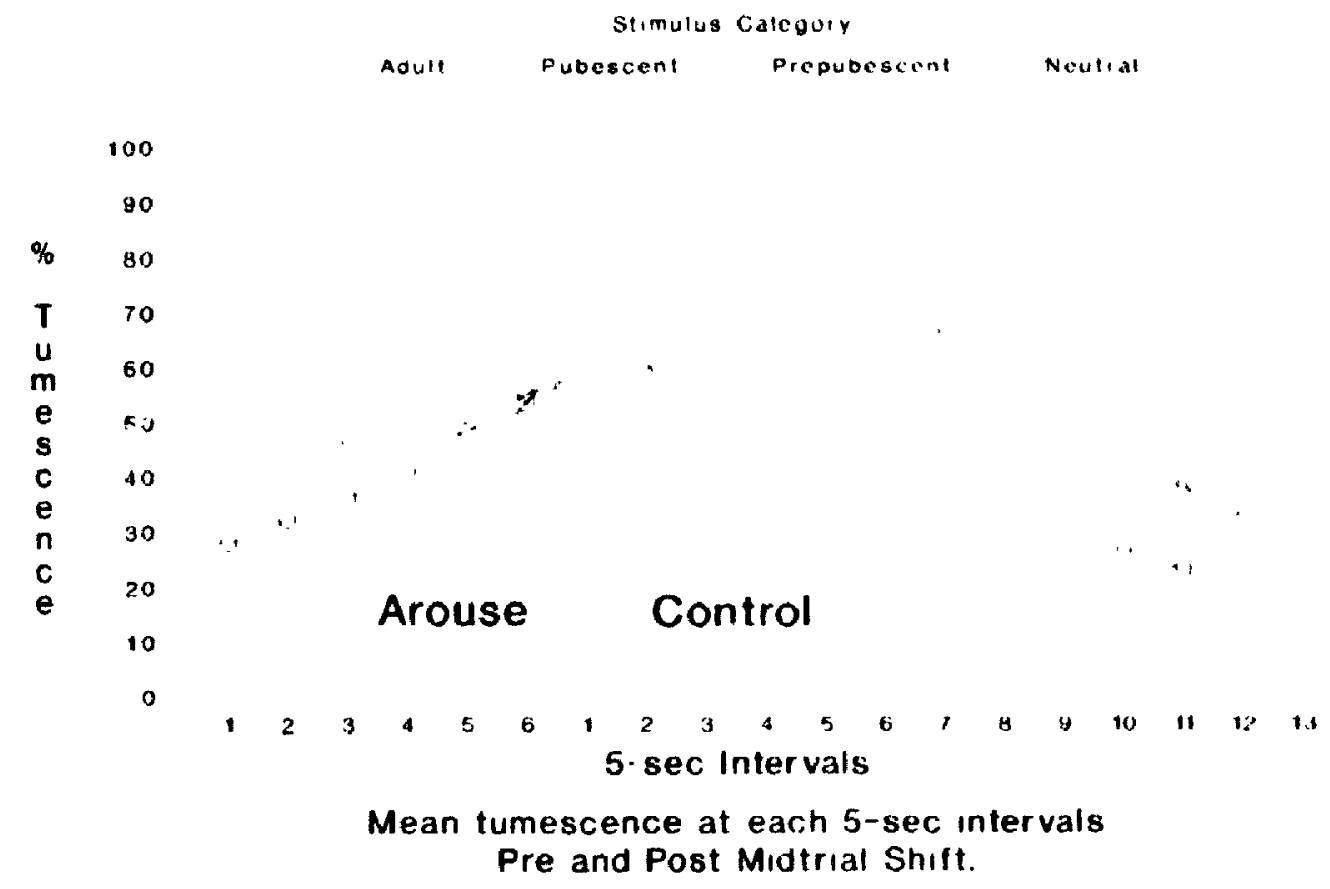

CVSO-2

Averaged Within Stimulus Category

Stimulus Category
Adult Pubescent Prepubescent Nrultal

100

90

$\% 80$

T 70

m 60

e 50

c 40

e 30

C $\quad 30$

10

10

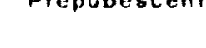




\section{CVSO-3}

Averaged Within Stimulus Category
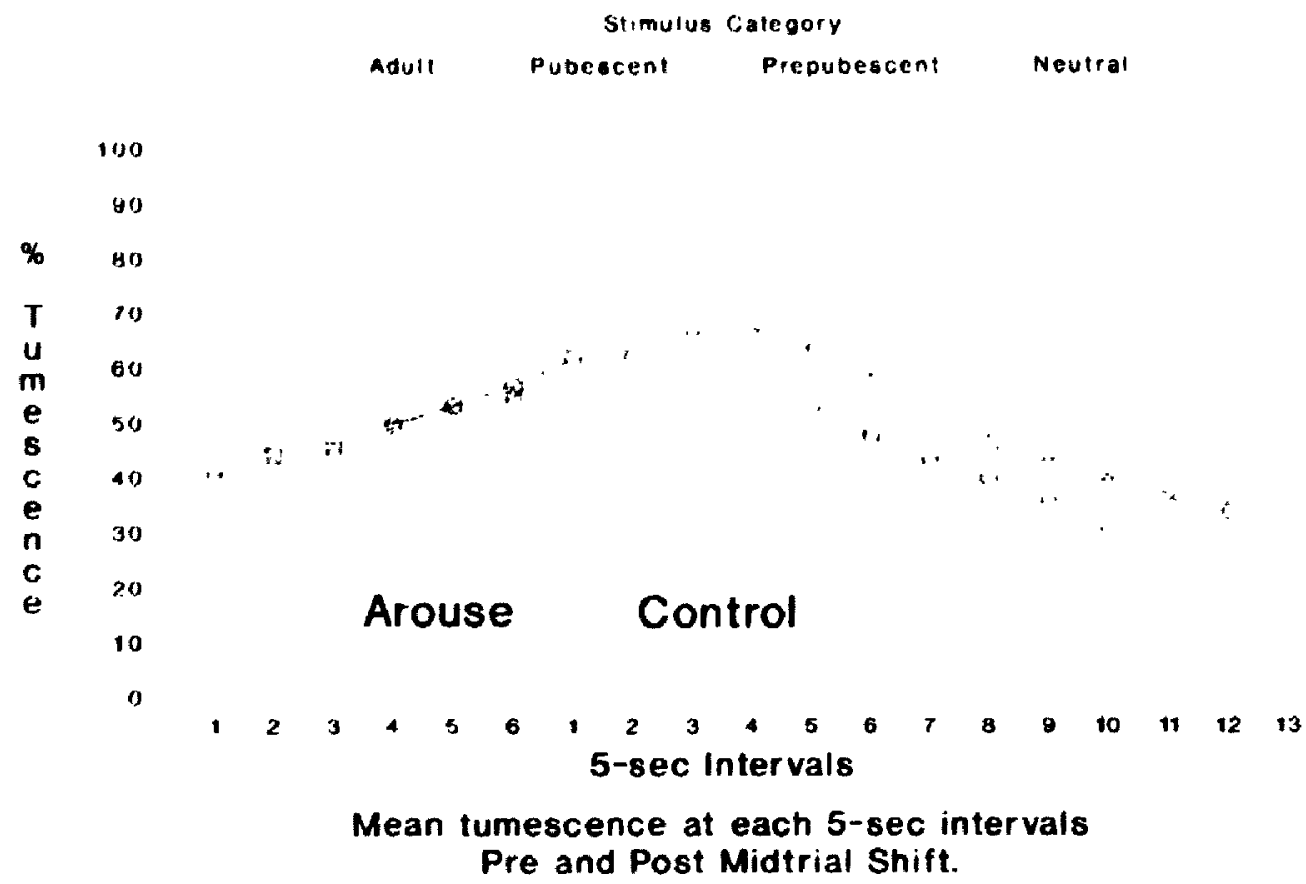

CVSO-4

Averaged Within Stimulus Category

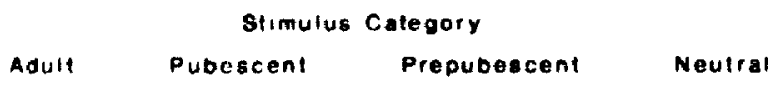

100

90

Arouse Control 
CVSO-5

Averaged Within Stimulus Category

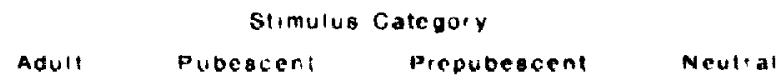

100

80

\% $8 \mathrm{c}$

$7 \quad 70$

1860

e 50

$\mathbf{s}$

c

e

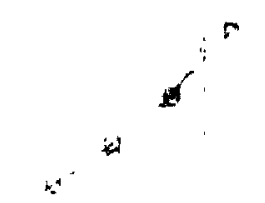

\section{Arouse Control}

12

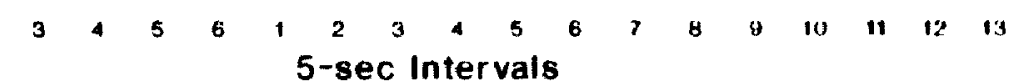

\section{CVSO-6 \\ Averaged Within Stimulus Category}

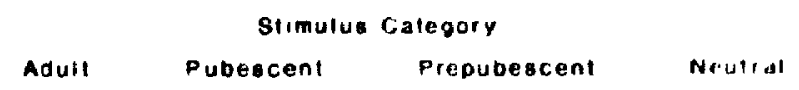

100

80

$\% 80$

T 70

m 60

e 50

c

e 30

c 20

10

Arouse Control

0

$$
\text { 5-sec Intervals }
$$

Mean tumescence at each 5-8ec intervals

Pre and Post Midtrial Shift. 
CVSO-7

Averaged Within Stimulus Category

Stimulue Category
Adult Pubeccent Prepubeocent Neutral

100

90

bo

10

60

50

40

30

20

10

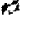

Arouse Control

o)
$\begin{array}{lllllllllllllllllll}1 & 2 & 3 & 4 & 5 & 6 & 1 & 2 & 3 & 4 & 5 & 6 & 7 & 8 & 9 & 10 & 11 & 12 & 13\end{array}$ 5-sec Intervals

Mean tumescence at each 5-sec intervals Pre and Post Midtrial Shift.

\section{CVSO-8}

Averaged Within Stimulus Category

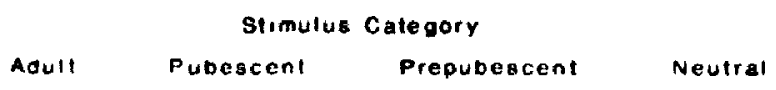

100

90

Arouse Control

1

(3)

$$
5-\sec \text { Intervals }
$$

Mean tumescence at each 5-sec intervals Pre and Post Midtrial Shift. 
CVSO-9

Averaged Within Stimulus Category

Stimulus Catcoory
Adutt Pubescent Propubecent Neutia:

100

80

$\% 80$

T 70

m 60

e 50

s 40

e 30

c 20

10

Arouse Control

12

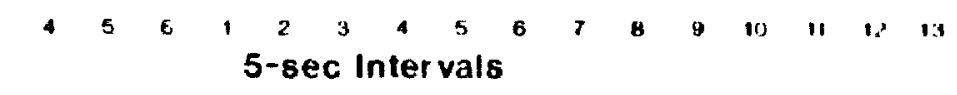

Mean tumescence at each 5-sec intervals

Pre and Post Midtrial Shift.

\section{CVSO-10 \\ Averaged Within Stimulus Category}

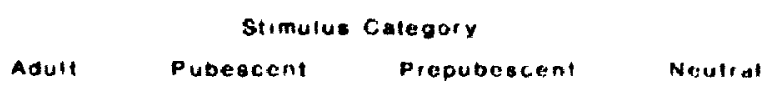

100

90

$\%$

Bo

70

60

50

40

30

20

10

Arouse Control

o

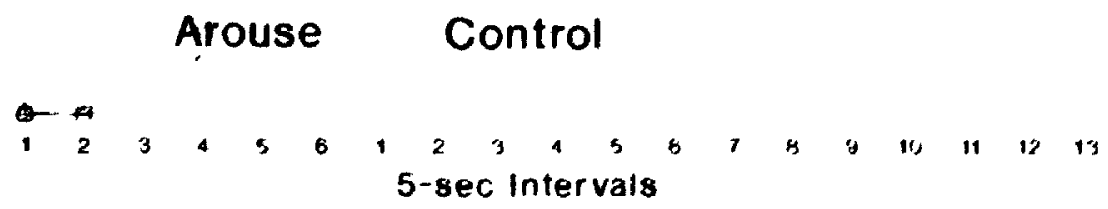

Mean tumescence at each 5-sec intervals

Pre and Post Midtrial Shift. 


\section{Control of Penile Tumescence}

69

Appendix E

ADULT VICTIM GROUP INDIVIDUAL DATA 
AVSO-1

Averaged Within Stimulus Category

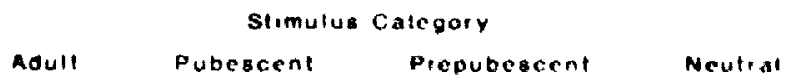

100

80

70

60

50

40

30

20

10

Arouse Control

o

$$
\text { 5-sec intervals }
$$

Mean tumescence at each 5-sec intervals

Pre and Post Midtrial Shift.

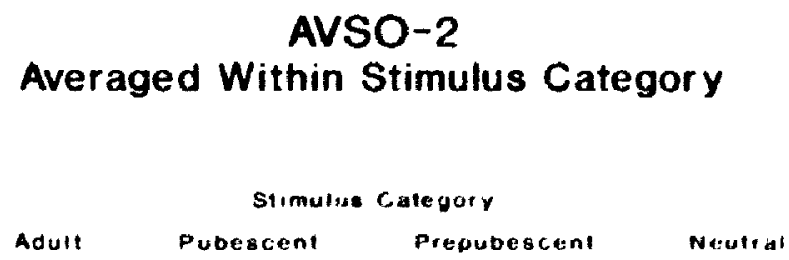

100

90

80

70

60

50

40

30

20

10

Arouse Control

D

1

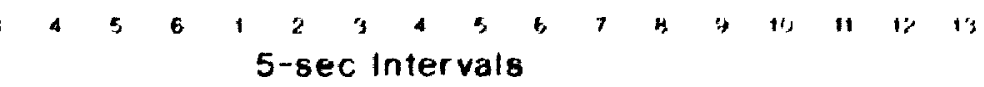

Mean tumescence at each 5-sec intervals

Pre and Post Midtrial Shift.
} 
AVSO-3

Averaged Within Stimulus Category
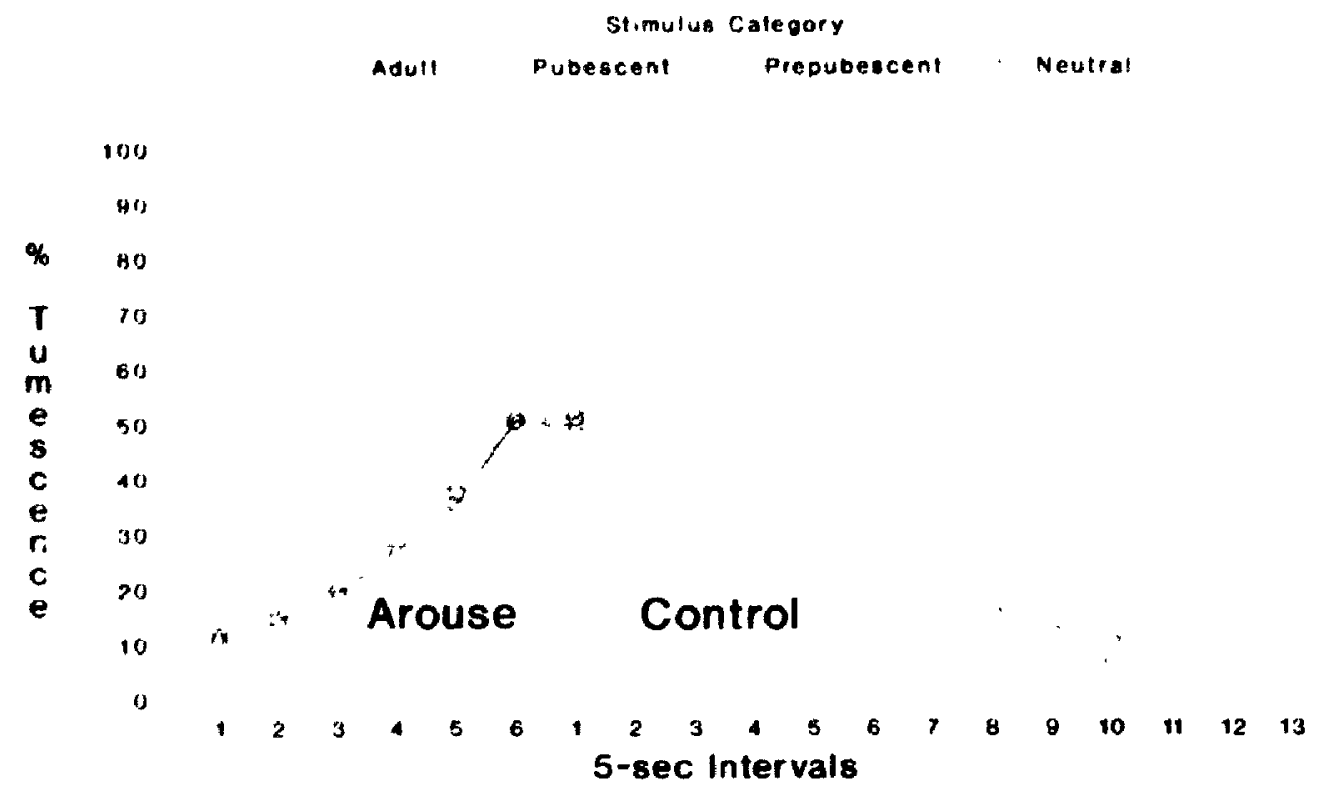

Mean tumescence at each 5-8ec intervals

Pre and Post Midtrial Shift.

AVSO-4
Averaged Within Stimulus Category

Stimulus Category
Adult Pubescent Prepubescent Neutrat

100

90

$\% 80$

T 70

46

e so

8

C 40

n 30

e 20

10

$\therefore$ Arouse Control

0

12

3

2
$5-s e c$

Mean tumescence at each 5-sec intervals

Pre and Post Midtrial Shift. 


\section{AVSO-5 \\ Averaged Within Stimulus Category}

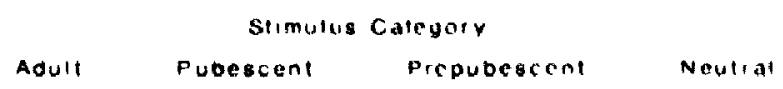

100

90

$\%$

$7 \quad 70$

$\mathrm{u} \quad 60$

e 50

C 40

e

n 30

e 20

10

0

Pubescent

prepubescent

Neutiat

(n)

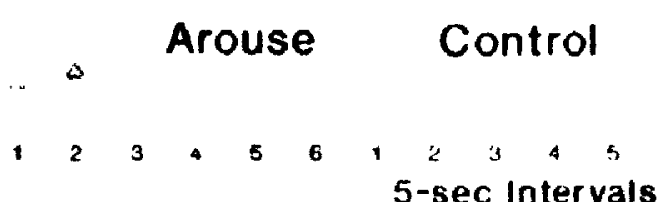

Pre and Post Midtrial Shilt.

\section{AVSO-6 \\ Averaged Within Stimulus Category}

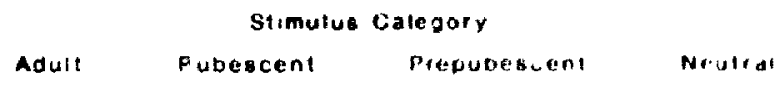

100

Arouse Controi

0 
AVSO-7

Averaged Within Stimulus: Category

Stimulus Categr-y
Adull Pubeccent Prepubesconl Neutral

100

(a)

sor

70

61)

50

$\infty$

t)

B

$\because$

30

20

10

Árouse Control

,

$$
\text { 5-sec Intervals }
$$

Mean tumescence at each 5-sec intervals

Pre and Post Midirial Shift.

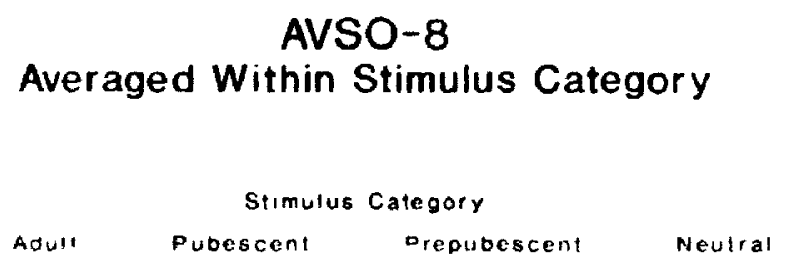

Adull

Drepubescent

Neutral

100

40

4

m

e

S

C $\quad 40$

n 30

c 20

10

n)

\section{Arouse Control}

Mean tumescence at each 5-sec intervals Pre and Post Midtrial Shift. 
AVSO-9

Averaged Within Stimulus Category

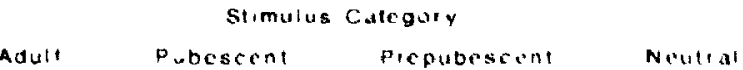

100

90

80

70

60

50

40

30

20

fo

Arouse Control

0

pubescent

piepubesermt

Nential

23

c.

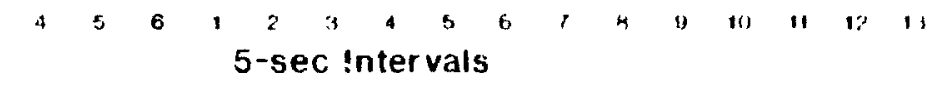

Mean tumescence at each 5-sec intervals

Pre and Post Midtrial Snift.

AVSO-10

Averaged Within Stimulus Category

Stimulus Category
Aduli Pubescent Fepubristent Nrutral

100

90

$\%$

80

70

60

50)

40

30

20

$: 0$

Arouse Control

0

$$
\text { 5-sec Intervals }
$$

Mean tumescence at each 5-sec intervals Pre ant. Pos: Midtrial Shift 

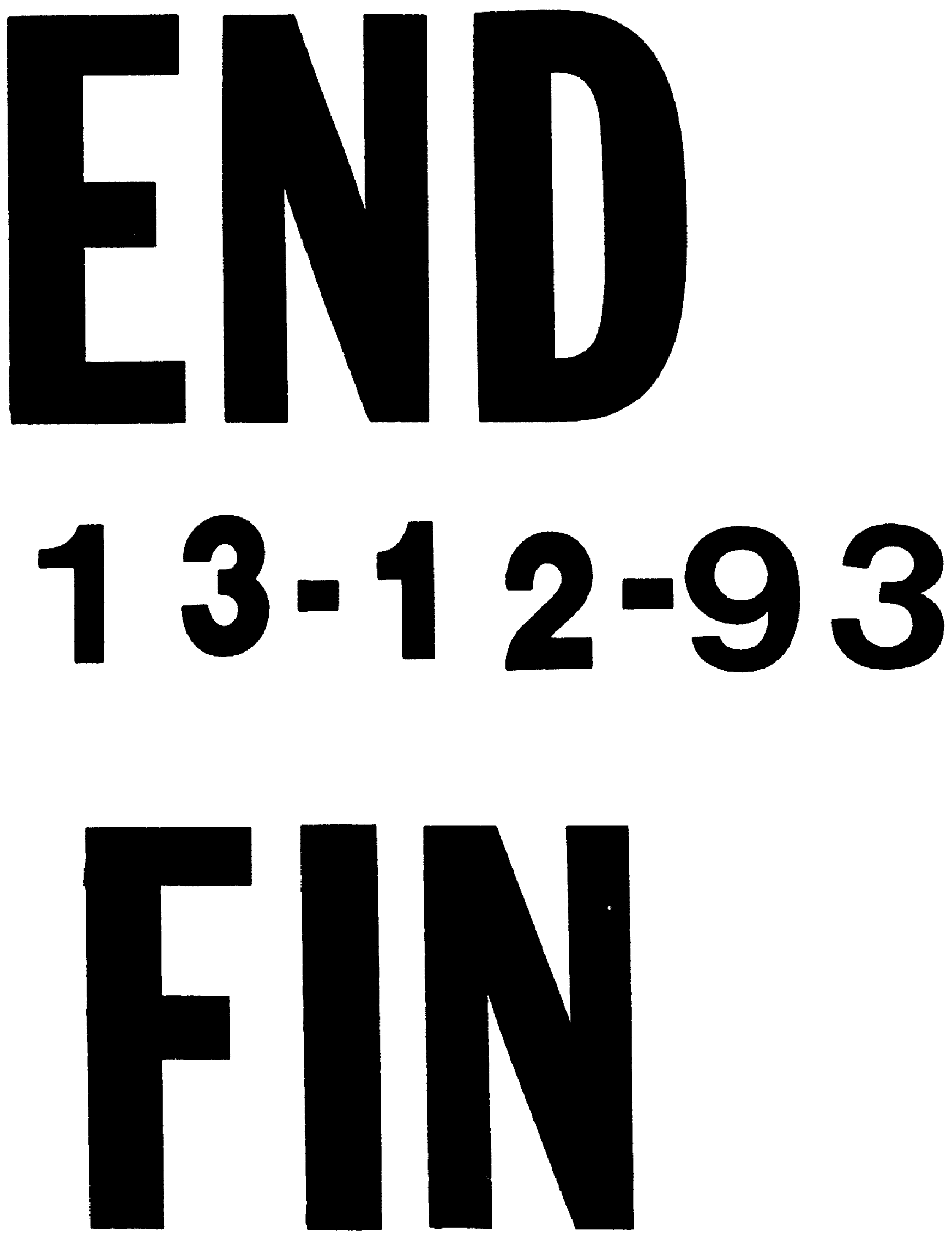